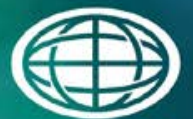

Savannah River

National Laboratory ${ }^{m}$

OPERATED BY SAVANNAH RIVER NUCLEAR SOLUTIONS

\title{
Sensitivity Analysis for Saltstone Disposal Unit Column Degradation Analyses
}

G. P. Flach

G. A. Taylor

October 2014

SRNL-STI-2014-00505, Revision 0 


\section{DISCLAIMER}

This work was prepared under an agreement with and funded by the U.S. Government. Neither the U.S. Government or its employees, nor any of its contractors, subcontractors or their employees, makes any express or implied:

1. warranty or assumes any legal liability for the accuracy, completeness, or for the use or results of such use of any information, product, or process disclosed; or

2. representation that such use or results of such use would not infringe privately owned rights; or

3. endorsement or recommendation of any specifically identified commercial product, process, or service.

Any views and opinions of authors expressed in this work do not necessarily state or reflect those of the United States Government, or its contractors, or subcontractors.

\section{Printed in the United States of America \\ Prepared for U.S. Department of Energy}




\title{
Sensitivity Analysis for Saltstone Disposal Unit Column Degradation Analyses
}

\author{
G. P. Flach \\ G. A. Taylor
}

October 2014 


\section{REVIEWS AND APPROVALS}

\section{AUTHORS:}

TECHNICAL REVIEW:

F. G. Smith, Process Modeling \& Computational Chemistry

Environmental Restoration Technologies 


\section{REVISIONS}

$\begin{array}{cl}\text { Revision } & \text { Description } \\ 0 & \text { Original issue }\end{array}$ 


\section{EXECUTIVE SUMMARY}

PORFLOW related analyses supporting a Sensitivity Analysis for Saltstone Disposal Unit (SDU) column degradation were performed. Previous analyses, Flach and Taylor 2014, used a model in which the SDU columns degraded in a piecewise manner from the top and bottom simultaneously. The current analyses employs a model in which all pieces of the column degrade at the same time. Information was extracted from the analyses which may be useful in determining the distribution of Tc-99 in the various SDUs throughout time and in determining flow balances for the SDUs. 


\section{TABLE OF CONTENTS}

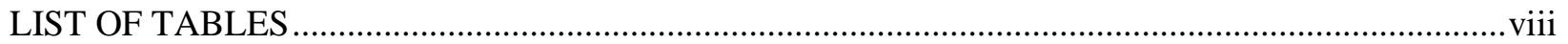

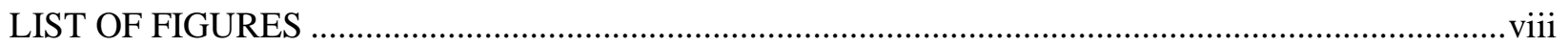

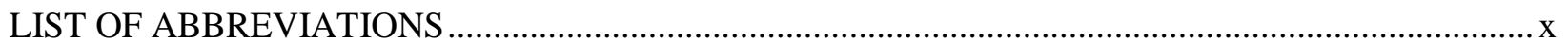

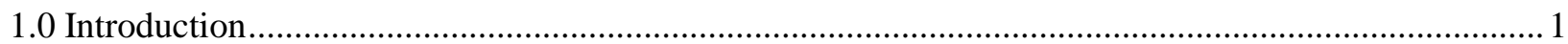

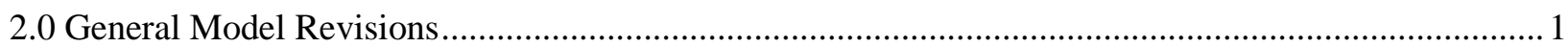

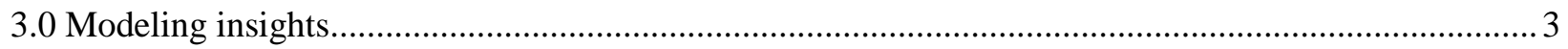

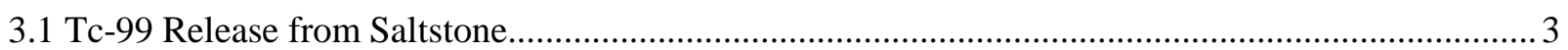

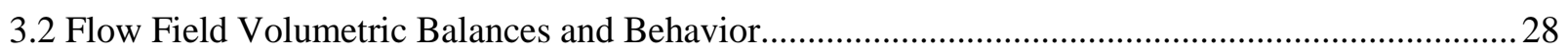

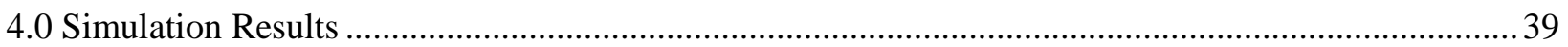

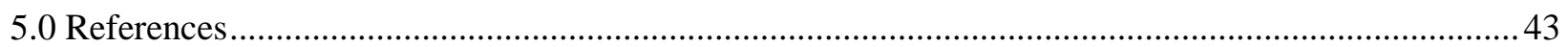




\section{LIST OF TABLES}

Table 2-1. Cementitious material degradation times (Flach and Smith 2014)......................................... 2

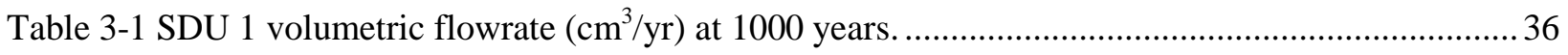

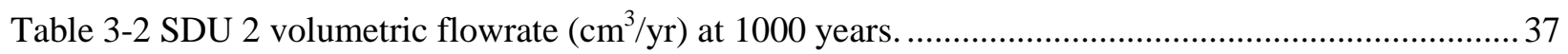

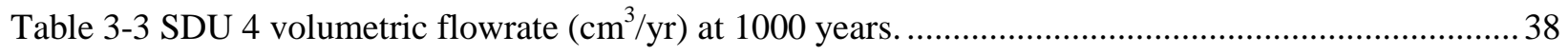

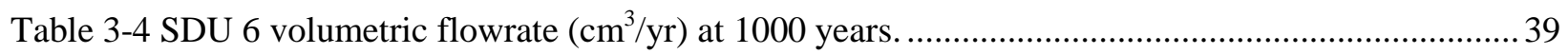

\section{LIST OF FIGURES}

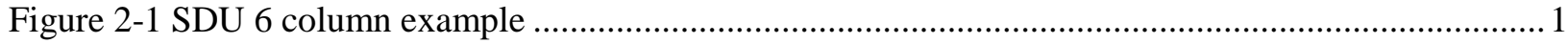

Figure 3-1 SDU 6 saturation and flow field for the $0-50$ year time interval............................................ 6

Figure 3-2 SDU 6 saturation and flow field for the 979-1128 year time interval..................................... 7

Figure 3-3 SDU 6 saturation and flow field for the 4917-5209 year time interval.................................. 8

Figure 3-4 SDU 6 saturation and flow field for the 9500-10000 year time interval................................ 9

Figure 3-5 SDU 6 saturation and flow field for the 13459-15000 year time interval.............................. 10

Figure 3-6 SDU 6 saturation and flow field for the 19500-20000 year time interval..............................11

Figure 3-7 SDU 6 saturation and flow field for the 50000-100000 year time interval............................ 12

Figure 3-8 Tc-99, oxygen and reduction capacity at 0 yr with Tc release rate..................................... 13

Figure 3-9 Tc-99, oxygen and reduction capacity at $100 \mathrm{yr}$ with Tc release rate.................................... 14

Figure 3-10 Tc-99, oxygen and reduction capacity at 1000 yr with Tc release rate................................ 15

Figure 3-11 Tc-99, oxygen and reduction capacity at 15000 yr with Tc release rate.............................. 16

Figure 3-12 Tc-99, oxygen and reduction capacity at 34000 yr with Tc release rate............................. 17

Figure 3-13 Tc-99, oxygen and reduction capacity at $34000 \mathrm{yr}$ with Tc release rate; detail view.............18

Figure 3-14 Tc-99, oxygen and reduction capacity at 38600 yr with Tc release rate..............................19

Figure 3-15 Tc-99, oxygen and reduction capacity at $38600 \mathrm{yr}$ with Tc release rate; detail view.............20

Figure 3-16 Tc-99 molar mass storage and cumulative decay and transport over time............................21

Figure 3-17 Tc-99 molar mass storage and cumulative decay and transport over time for saltstone layers;

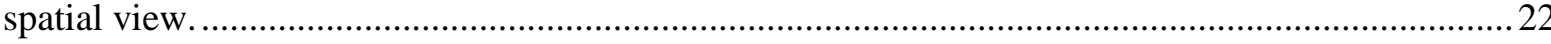

Figure 3-18 Tc-99 molar mass storage and cumulative decay and transport over time for saltstone layers; mechanism view. 


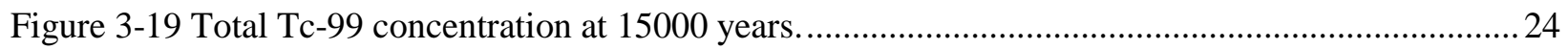

Figure 3-20 Total Tc-99 concentration at 30000 years........................................................................ 25

Figure 3-21 Total, solid-phase, and liquid-phase Tc-99 concentrations for SDU 6 cementitious materials

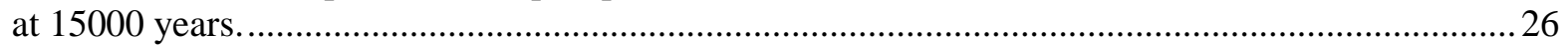

Figure 3-22 Total, solid-phase, and liquid-phase Tc-99 concentrations for SDU 6 cementitious materials

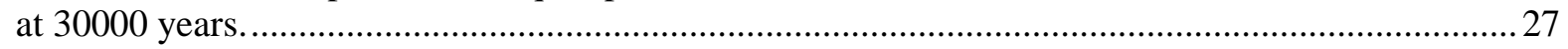

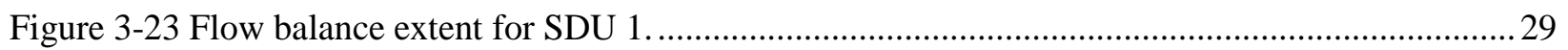

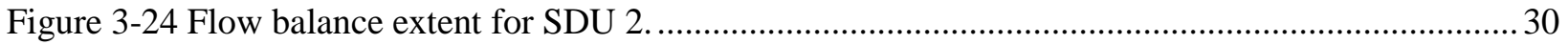

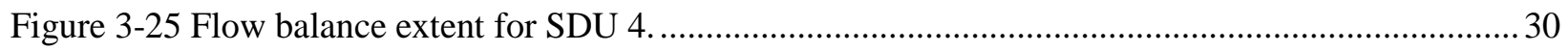

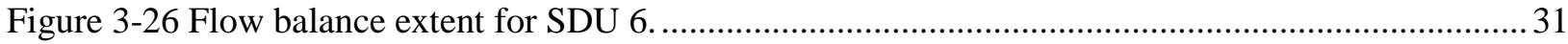

Figure 3-27 SDU 1 flow rate transient and flow field views.at 1000 years............................................. 32

Figure 3-28 SDU 2 flow rate transient and flow field views.at 1000 years............................................ 33

Figure 3-29 SDU 4 flow rate transient and flow field views.at 1000 years............................................. 34

Figure 3-30 SDU 6 flow rate transient and flow field views.at 1000 years............................................ 35

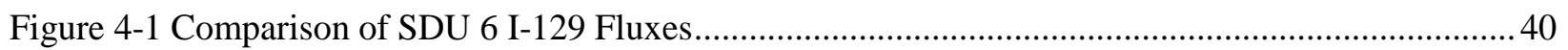

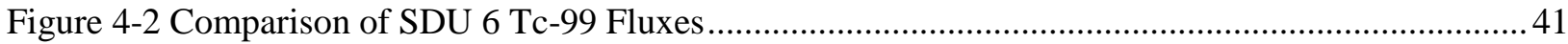

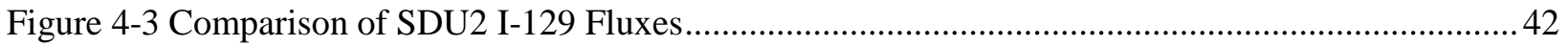

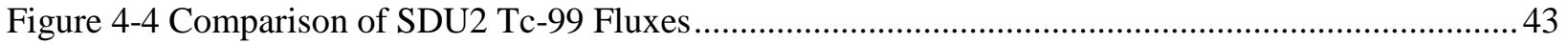




\section{LIST OF ABBREVIATIONS}

$\begin{array}{ll}\text { BE } & \text { Best Estimate } \\ \text { FY } & \text { Fiscal Year } \\ \text { GCL } & \text { Geosynthetic Clay Liner } \\ \text { HDPE } & \text { High Density Polyethylene } \\ \text { NV } & \text { Nominal Value } \\ \text { SA } & \text { Special Analysis } \\ \text { SDU } & \text { Saltstone Disposal Unit } \\ \text { SRNL } & \text { Savannah River National Laboratory } \\ \text { SRR } & \text { Savannah River Remediation }\end{array}$




\subsection{Introduction}

PORFLOW related analyses supporting SDU column degradation sensitivity analyses described herein are based on PORFLOW modeling (Flach and Taylor 2014) supporting the Saltstone FY14 SA. Modeling scenarios, key inputs, and work scope are specified in the Task Technical Request (Rosenberger 2014) and Task Technical \& Quality Assurance Plan (Taylor 2014). The notable change to the previous round of simulations is a modification to the column degradation paradigm. The previous round used a model in which the SDU columns degraded in a piecewise manner from the top and bottom simultaneously. The current round employs a model in which all pieces of the column degrade at the same time. Note that only SDU2 and SDU6 have columns which are affected by this change. A minor change was also made to a molecular weight affecting the SDU6 wall initial condition.

Based on recent experimental results, SRNL met with SRR to discuss concerns with the shrinking core conceptual model for Tc and slag oxidation and the need for additional experimental data. SRR requested that SRNL use the existing shrinking core model until results from the ongoing and planned experimental testing are available to revise the conceptual model, if needed. SRNL has not reviewed SRR's experimental test plans or data.

\subsection{General Model Revisions}

Two modeling revisions are related to this sensitivity study. First, a correction to a minor molecular weight error embedded in the SDU 6 estimates of initial $(t=0)$ wall degradation was corrected (Flach and Smith 2014). Second, the column degradation paradigm was changed. In previous analyses the column segments (as illustrated in Figure 2-1) degraded in a stepwise manner. Degradation began in both the top and bottom segments and then progressed toward the center in a symmetric manner. In the current analyses, all segments commence degradation at the same time and degrade at the same rate due to the inclusion of the sulfate attack mechanism (as shown in Table 2-1).

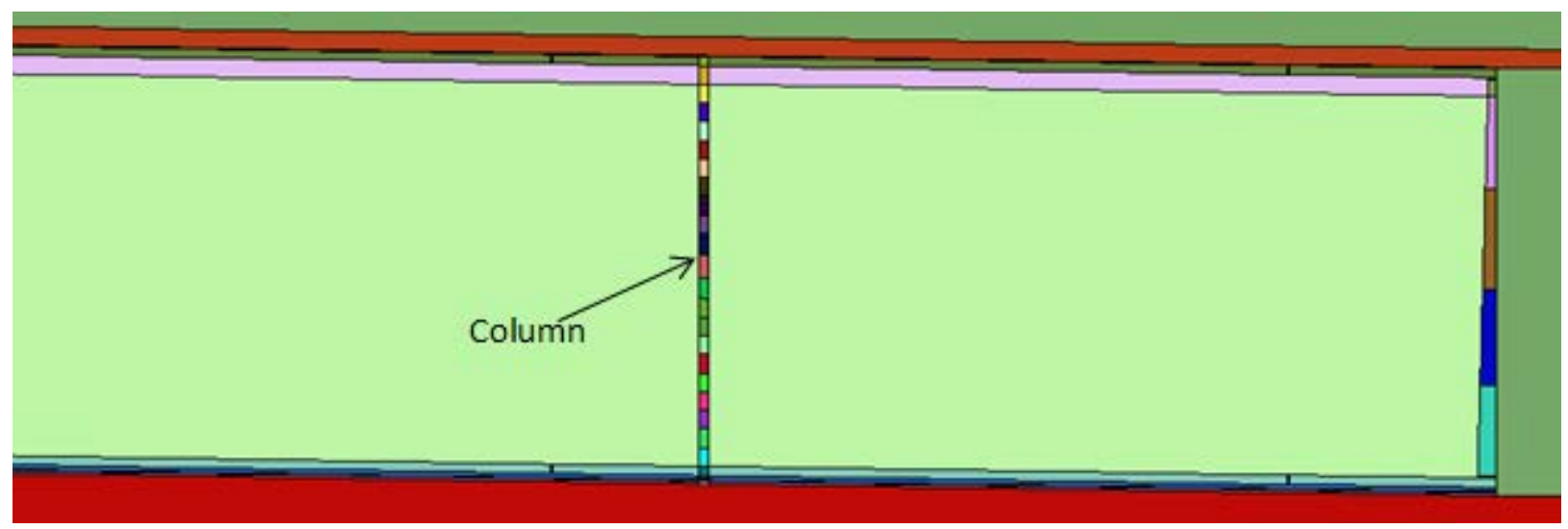

Figure 2-1 SDU 6 column example 
SRNL-STI-2014-00505

Revision 0

Table 2-1. Cementitious material degradation times (Flach and Smith 2014).

\begin{tabular}{|c|c|c|c|c|c|c|c|c|}
\hline \multirow[b]{3}{*}{ Component } & \multicolumn{4}{|c|}{ SDU6 } & \multicolumn{4}{|c|}{ SDU2 } \\
\hline & \multicolumn{2}{|c|}{ Thickness: } & \multirow{2}{*}{$\begin{array}{l}\text { NV } \\
\text { (yr) }\end{array}$} & \multirow{2}{*}{$\begin{array}{c}\text { BE } \\
(y r)\end{array}$} & \multicolumn{2}{|c|}{ Thickness: } & \multirow{2}{*}{$\begin{array}{l}\text { NV } \\
(y r)\end{array}$} & \multirow{2}{*}{$\begin{array}{c}\text { BE } \\
(y r)\end{array}$} \\
\hline & (in) & $(\mathrm{cm})$ & & & (in) & $(\mathrm{cm})$ & & \\
\hline Roof delay & & & 0 & 1400 & & & 0 & 0 \\
\hline Roof delay+degradation & 12 & 30.48 & 1413 & 2717 & 8 & 20.32 & 961 & 1820 \\
\hline FlooruMM delay & & & 0 & 1400 & & & 0 & 0 \\
\hline FloorUMM delay+degradation & 12 & 30.48 & 1413 & 2717 & 12 & 30.48 & 1413 & 2717 \\
\hline Wall delay & & & 0 & 0 & & & 0 & 0 \\
\hline Wall delay+degradation & 8.73 & 22.17 & 815 & 1933 & 8 & 20.32 & 922 & 1797 \\
\hline Wall delay & & & 0 & 0 & & & & \\
\hline Wall delay+degradation & 10.45 & 26.54 & 979 & 2324 & & & & \\
\hline Wall delay & & & 0 & 0 & & & & \\
\hline Wall delay+degradation & 13.46 & 34.19 & 1261 & 3012 & & & & \\
\hline Wall delay & & & 0 & 0 & & & & \\
\hline Wall delay+degradation & 16.5 & 41.91 & 1546 & 3708 & & & & \\
\hline Wall delay & & & 0 & 0 & & & & \\
\hline Wall delay+degradation & 19.45 & 49.40 & 1822 & 4385 & & & & \\
\hline Grout delay & & & 1413 & & & & 961 & 1820 \\
\hline Grout delay+degradation & 516 & 1310.64 & 439398 & & 264 & 670.56 & 225047 & 2242676 \\
\hline Column delay & & & 0 & 0 & & & 0 & 0 \\
\hline Column delay+degradation & 10.63 & 27.00 & 1277 & 2487 & 6.2 & 15.75 & 745 & 1450 \\
\hline
\end{tabular}




\subsection{Modeling insights}

Section 3.1 provides insight into the movement and distribution of Tc-99 in the SDUs. Section 3.2 provides insight into the flow balances of the SDUs.

\subsection{Tc-99 Release from Saltstone}

Ground blast furnace slag is included in the saltstone dry mix to create reducing conditions. Reduced Tc (oxidation state IV) is relatively immobile with release limited by solubility at 1.e-8 $\mathrm{mol} / \mathrm{L}$; in contrast, oxidized Tc (VII) is relatively mobile with partitioning to the solid phase controlled by sorption with low $K_{d}=0.5-0.8 \mathrm{~mL} / \mathrm{g}$ depending on $\mathrm{pH}$ (Kaplan and Li 2013). The Eh transition from solubility control to minimal sorption is the primary chemical influence on Tc mobility. Sorption coefficient variability with $\mathrm{pH}$ under oxidized conditions is practically insignificant and PORFLOW simulations consider only the Eh effect (Flach and Taylor 2014, Section 3.0)..

Jordan and Flach (2013) and Flach and Taylor (2014) include discussions of slag oxidation (reduction capacity consumption), Tc mobility, and transport simulation results. The purpose of this discussion is to provide further insights into the controlling mechanisms and behavior of Tc release from saltstone through reducing concrete barriers. Simulation results are shown for the SDU 6 design and Case A + Column Degradation Sensitivity scenario, and similar behavior is observed for other disposal unit designs and scenarios.

Figure 3-1 through Figure 3-7 illustrate the SDU 6 saturation and flow velocity fields for selected time intervals: 0-50, 979-1128, 4917-5209, 9500-10000, 13459-15000, 19500-20000, and 50000-100000 years. Overall flow is very low immediately after facility cover system placement ( 0 yr) and gradually increased through time as the cap degrades. The saltstone and concrete barriers have lower saturated permeability than the surrounding backfill and much of the infiltration approaching the disposal unit bypasses it until later times. The roof includes two joints that act as fast-flow paths and locally increase water and dissolved oxygen ingress over much of the simulation period.

Figure 3-8 through Figure 3-15 illustrate Tc-99 aqueous concentration (“C”), oxygen concentration (“C2”), and reduction capacity / slag concentration (“C3”) for selected times: 0, 100, 1000, 15000, 34000, and 38600 years. Included in each composite figure is a plot of Tc-99 release to the water table. Figure 3-8 shows initial concentrations based on $K_{d}=1000 \mathrm{~mL} / \mathrm{g}$ prior to imposition of solubility control on Tc-99, which occurs after the first numerical time step. Figure 3-9 shows simulation results at 100 years and the Tc-99 concentration within saltstone is 1.e-8 $\mathrm{mol} / \mathrm{L}$ as expected. Little change is observed through 1000 years (Figure 3-10) because the infiltration rate and saltstone permeability are low.

Advection through the disposal unit has been significant for some time approaching 15000 years (Figure 3-11). At this time a distinct oxidation and Tc release front is observed in the upper portion of saltstone. The interface slopes downward from the centerline (left) to the outer radius (right) reflecting lateral diversion of infiltrating water through the sloped drainage layer above 
the roof. Perturbations about this trend are observed near the wall, roof support column, and roof joints. The higher permeability wall and column features draw water from the adjoining saltstone and locally slow downward flow and oxidation. Conversely, the high permeability roof joints increase flow into the saltstone and locally accelerate the oxidation front. Tc-99 is practically absent in the oxidized region above the front, having advected downward into the reduced zone and been re-partitioned to the solid phase just ahead of the front by the solubility limit on aqueous concentration. Tc-99 concentrations much higher than solubility are observed at the oxidation front. Below the oxidation front Tc-99 concentration coincides with solubility and the Tc-99 release rate is approximately the product of solubility, Darcy velocity (volumetric water flux on a total area basis) and cross-sectional area. The increase in the Tc-99 release rate through about 34000 years is a result of increased advection caused by cover system and cementitious material degradation.

Shortly after 34000 years an abrupt increase in Tc-99 release occurs. As indicated by Figure 3-12 and Figure 3-13, the leading edge of the oxidation front has just reached the permeable floor joints. Tc that has been concentrated ahead of the oxidation front begins to release to soil beneath the disposal unit and cross the water table. The peak release rate occurs near 38600 years, when a large portion of the oxidation front breaks through the floor (Figure 3-14 and Figure 3-15). The "noise" observed in the release rate transient is a result of numerical discretization and could be reduced through grid refinement if there were no limits on computer memory and runtime.

Figure 3-8 through Figure 3-15 only explicitly show the aqueous concentration of Tc-99, and inferences about the solid phase concentration were made in the above discussion. Figures 3-16 through 3-18 provide a total molar mass balance accounting for Tc-99 in both phases. In the PORFLOW unit radian simulation, the initial inventory of Tc-99 is approximately $350 \mathrm{~mol}$. Figure 3-16, upper left, shows the inventory in the model domain ("storage") declining over time primarily due to cumulative advective transport ("outAdv") and some radioactive decay (“decay"). Tc-99 storage in engineered barriers surrounding saltstone (Figure 3-16, lower left) is relatively low compared to the cumulative advective inflow and outflow curves (which nearly overlap). Most of the Tc-99 release occurs through the floor/basemat (Figure 3-16, lower right), although some occurs through the wall (Figure 3-16, upper right) and floor joints (not shown).

Figure 3-17 and Figure 3-18 provide mass balances for four sub-layers of the saltstone monolith. The sub-layer interfaces align with the wall segment interfaces and the layers have roughly equal volume and Tc-99 initial inventory. These figures show that Tc-99 released from an upper layer is recaptured in the lower layer before eventually being released again as the oxidation front advances from layer to layer. Further spatial detail is provided by Figure 3-19 and Figure 3-20 for two snapshots in time, 15000 and 30000 years. These figures are plots of total Tc-99 concentration (total molar mass / total volume) rather than aqueous Tc-99 concentration (molar mass in liquid / liquid volume) shown in preceding figures. The peak concentration near the oxidation front increases through time as Tc-99 released from oxidized zones is captured by reduced regions just ahead of the front. Figure 3-21 and Figure 3-22 show total, solid-phase (molar mass in solid / solid mass), and liquid-phase Tc-99 concentration within cementitious materials at 15000 and 30000 years respectively. The total and solid-phase concentrations within saltstone are numerically nearly identical because the grout bulk density is approximately $1 \mathrm{~kg} / \mathrm{L}$ and nearly all of the Tc-99 mass is partitioned to the solid-phase in reduced regions. 
SRNL-STI-2014-00505

Revision 0 


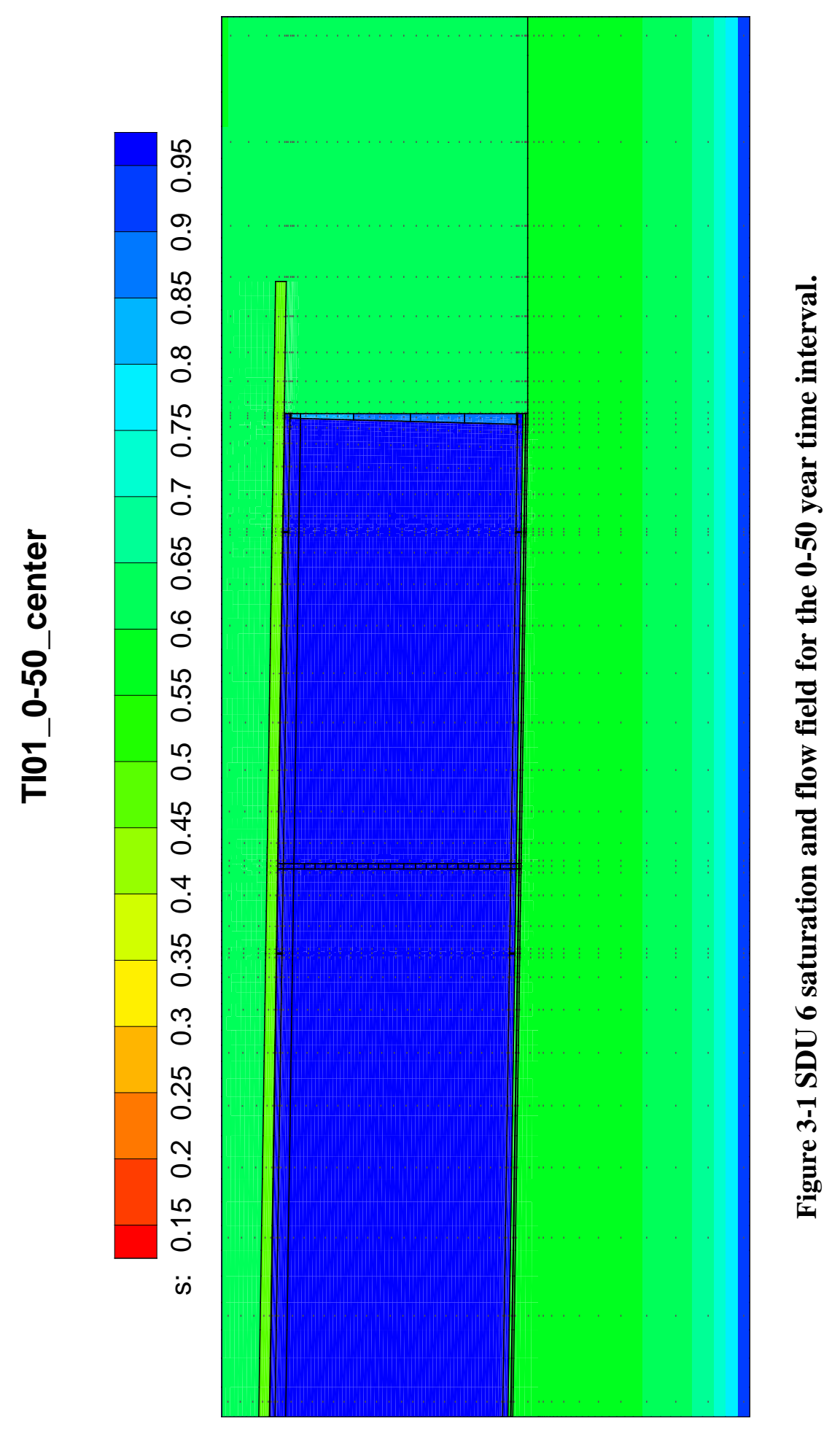




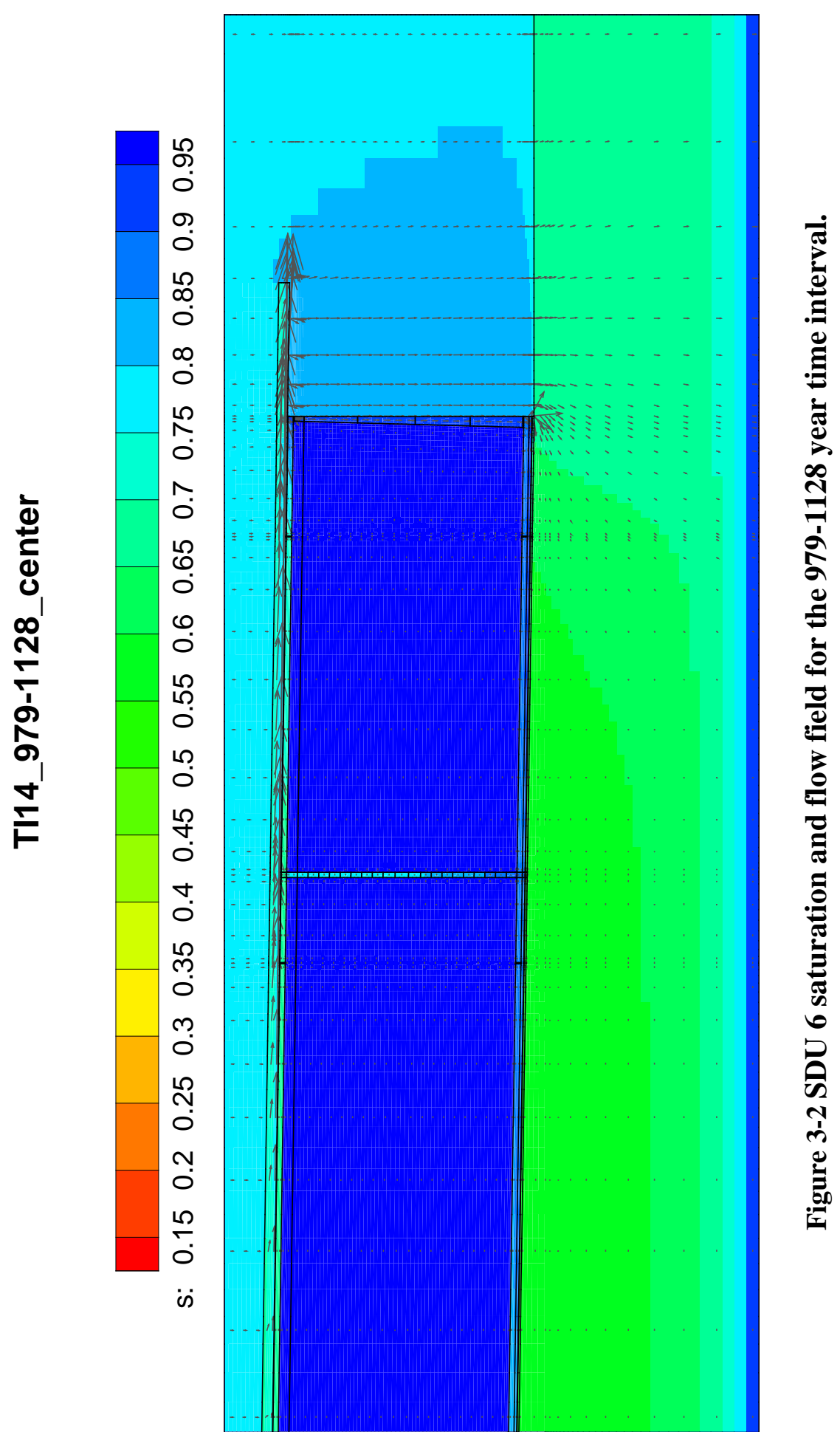




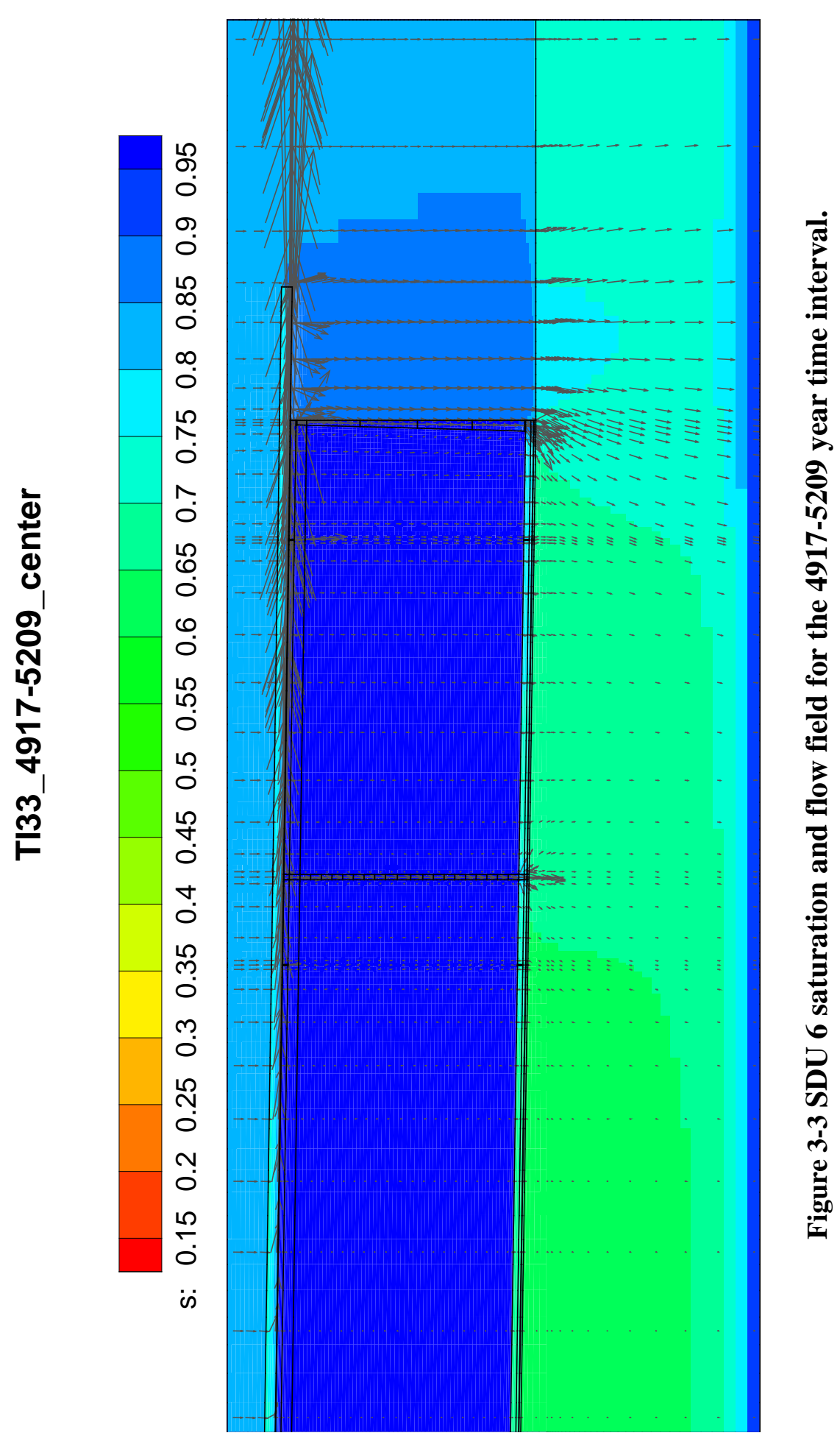




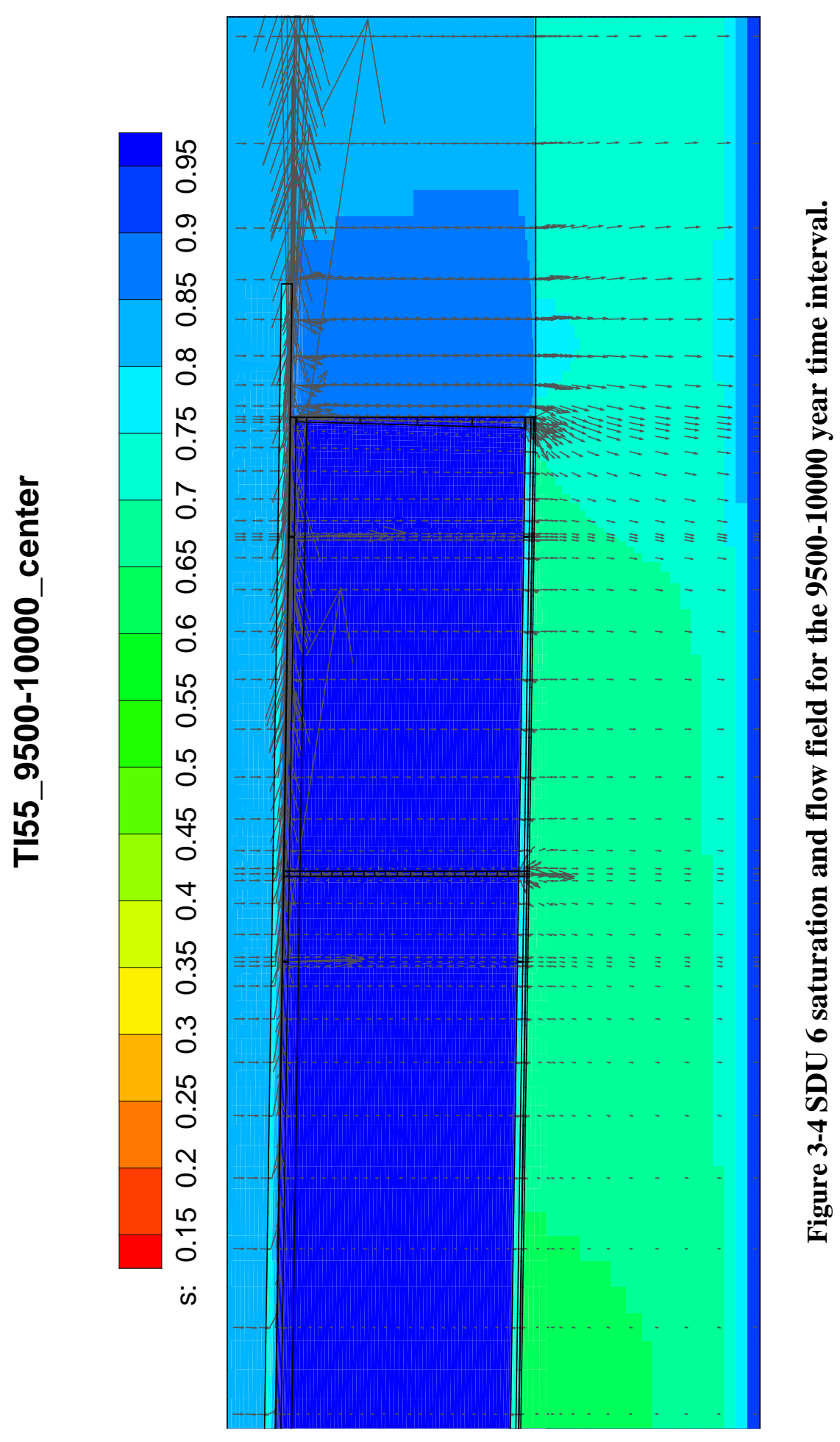




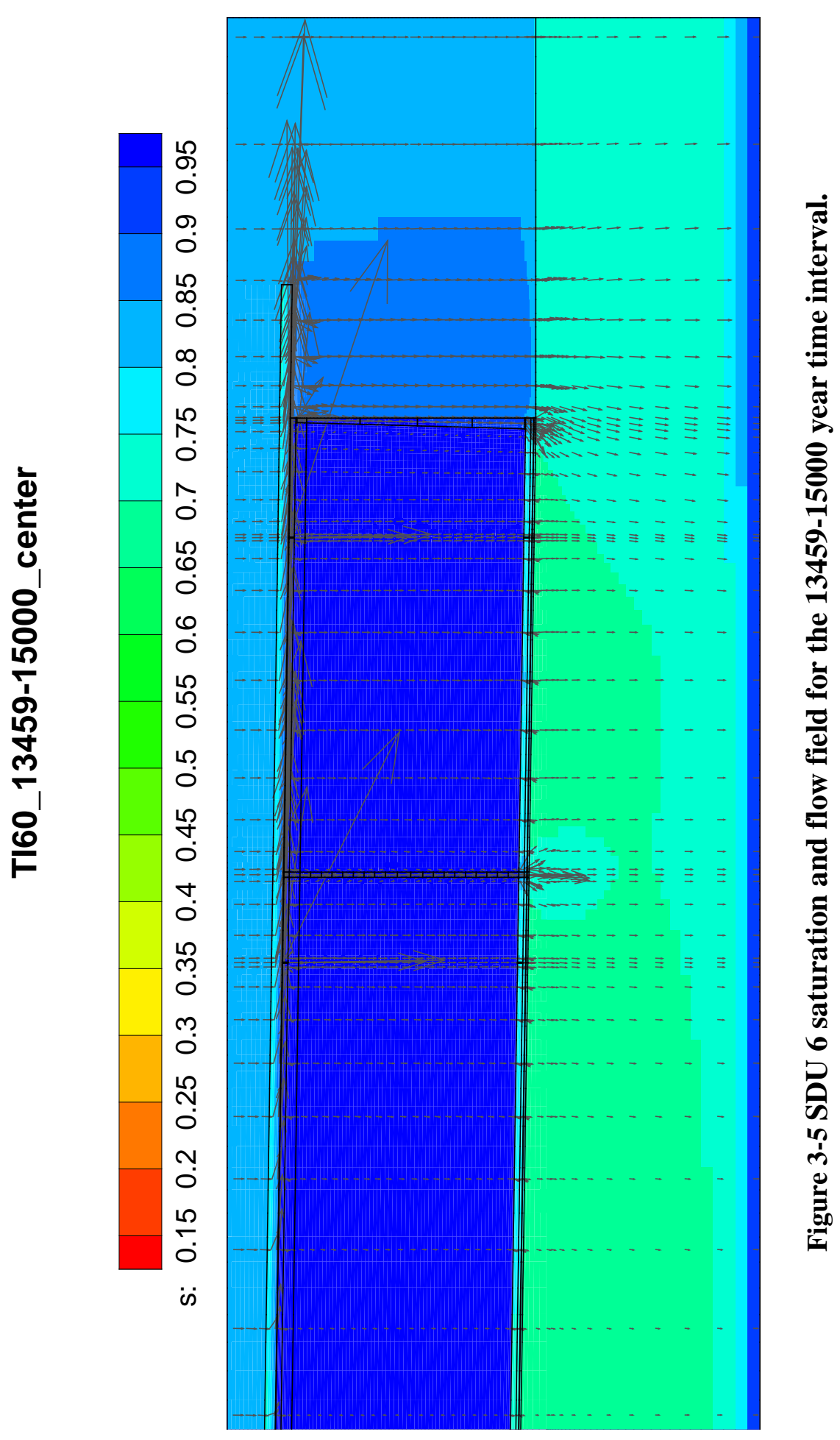




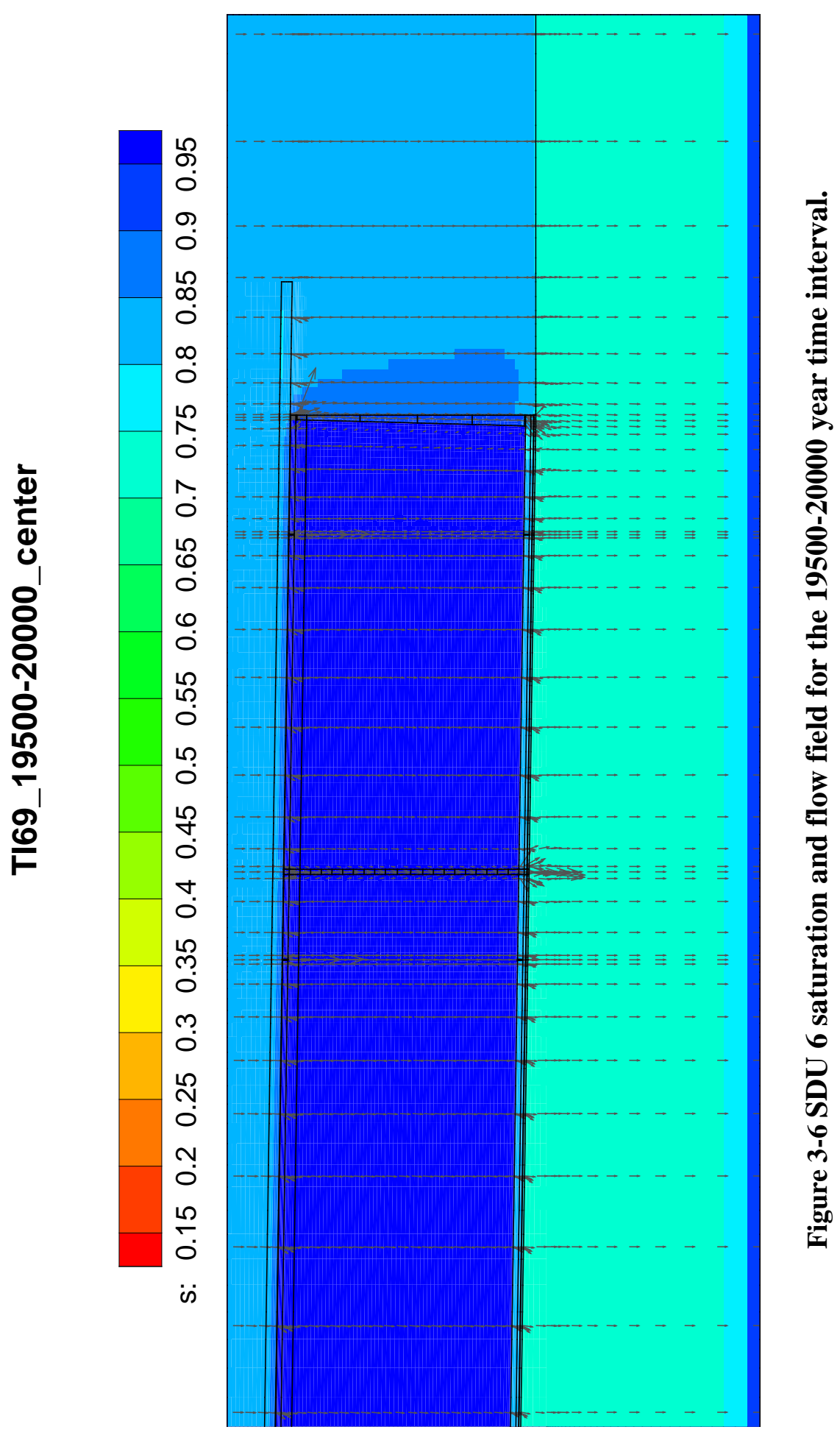




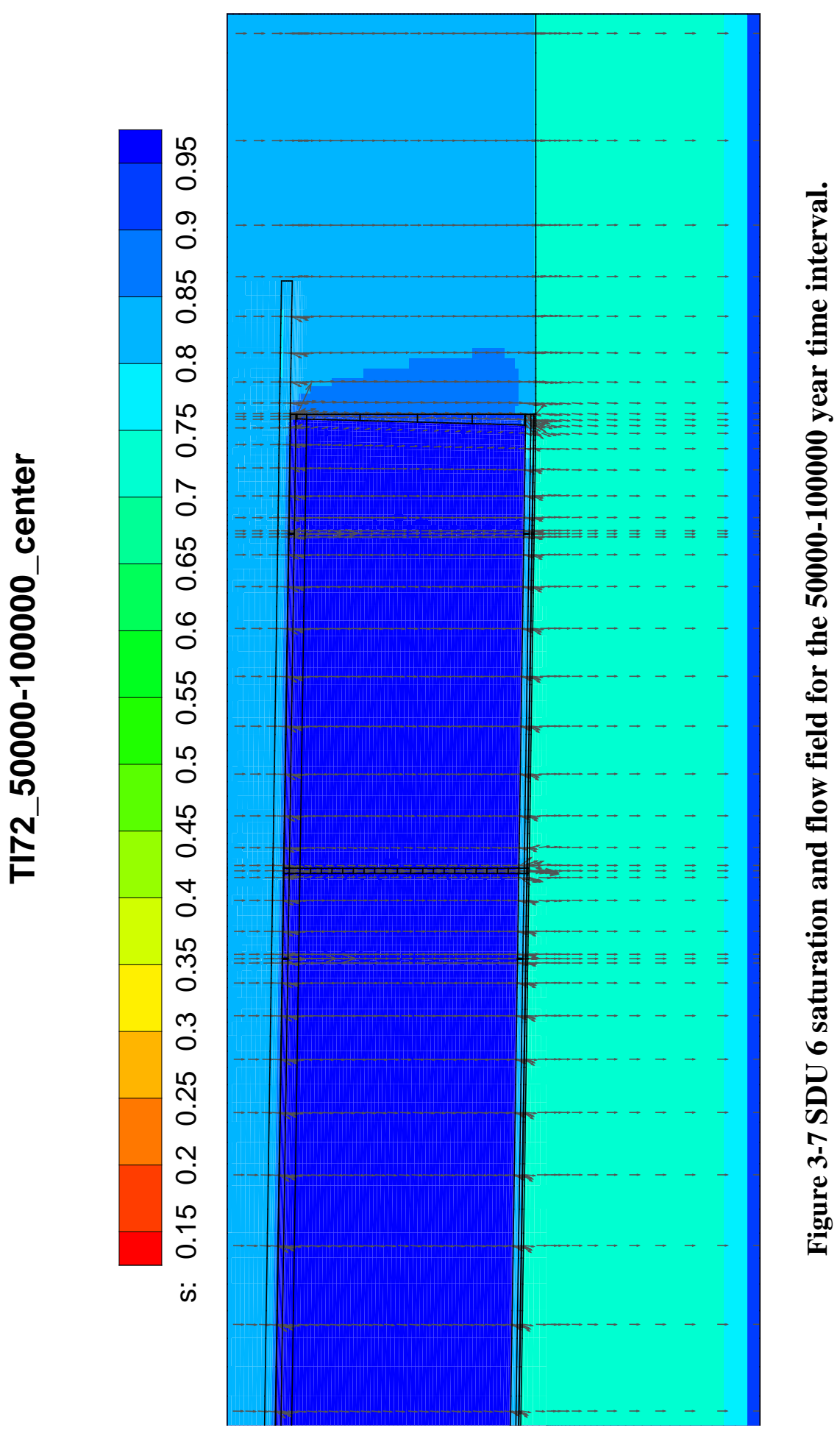




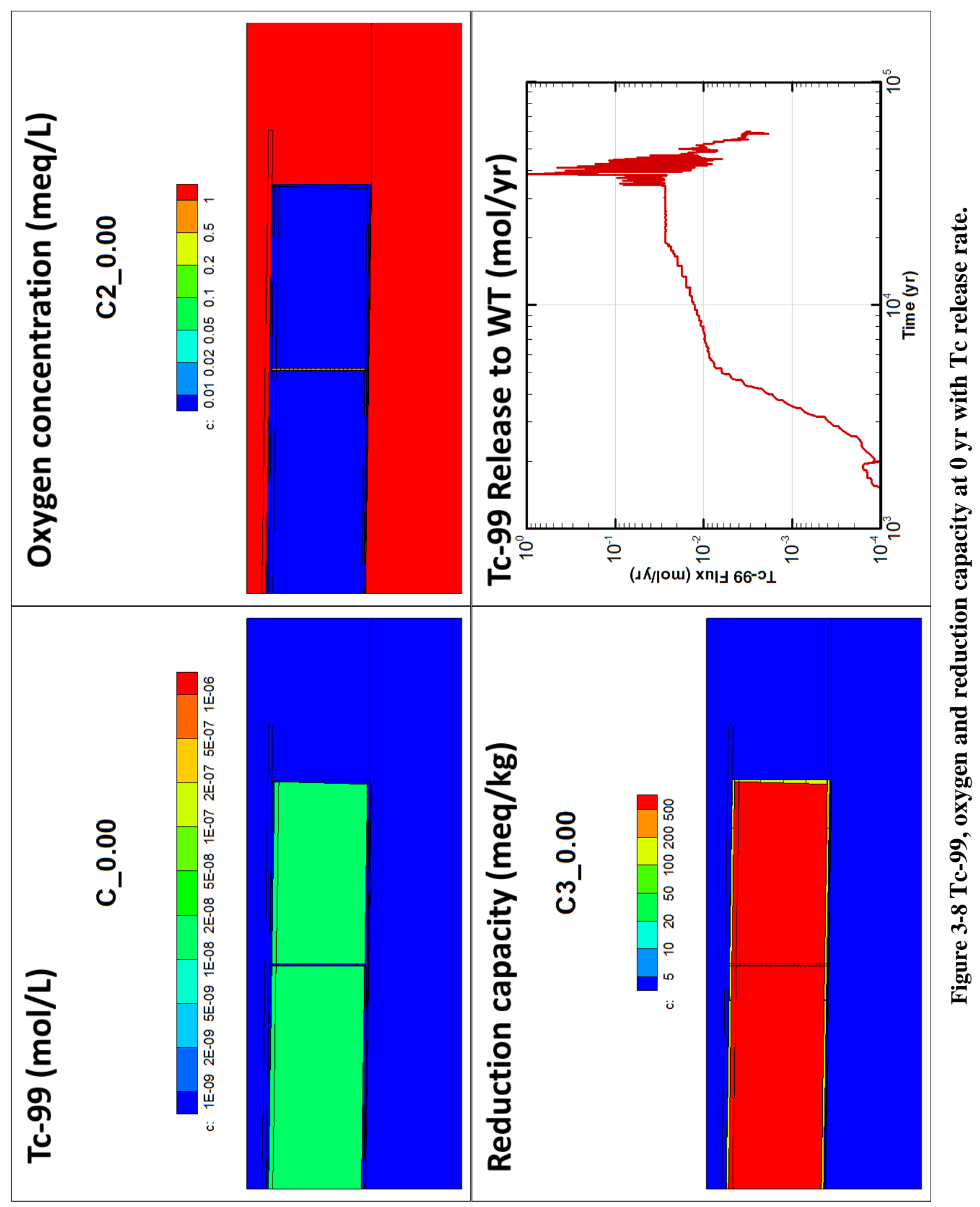




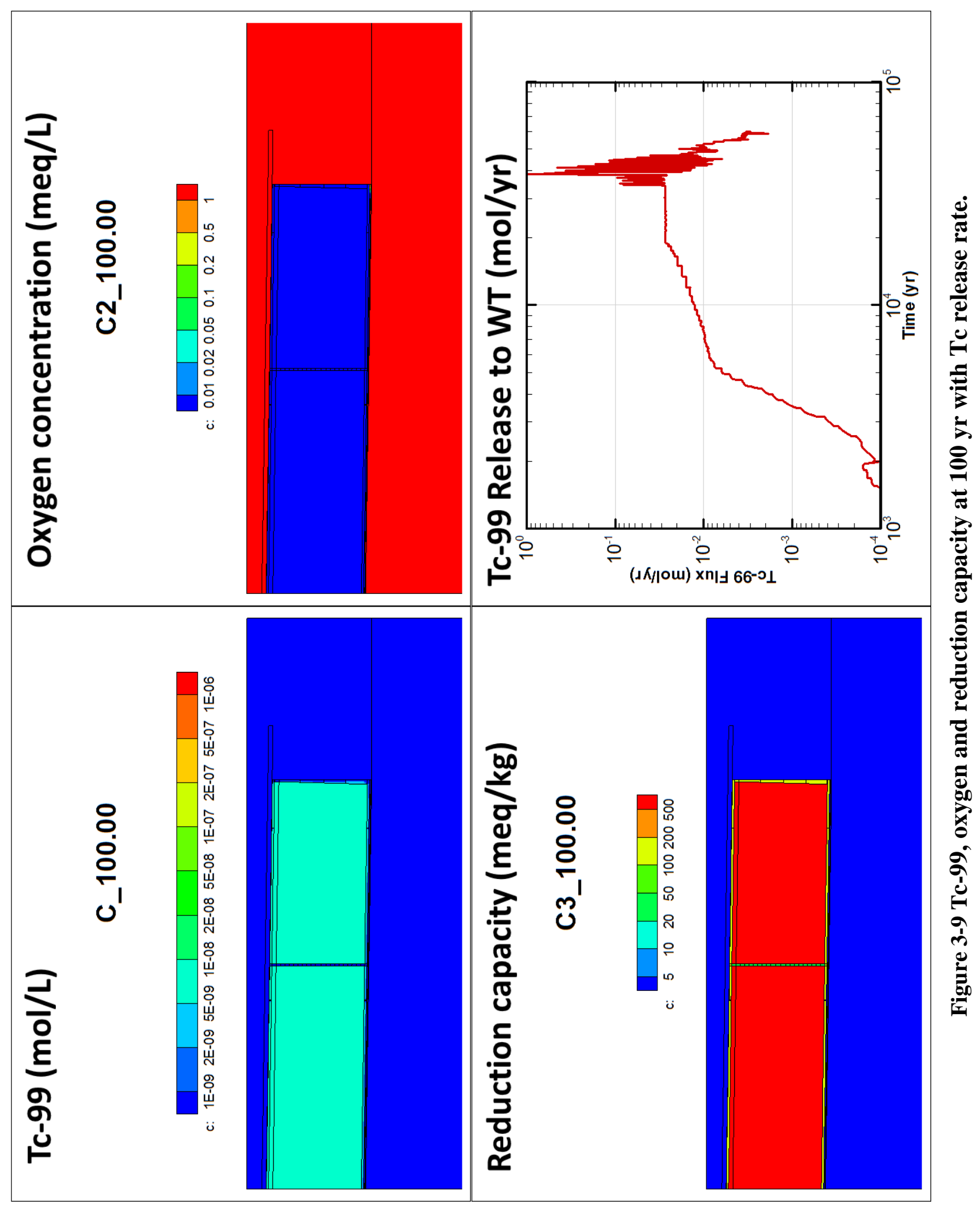




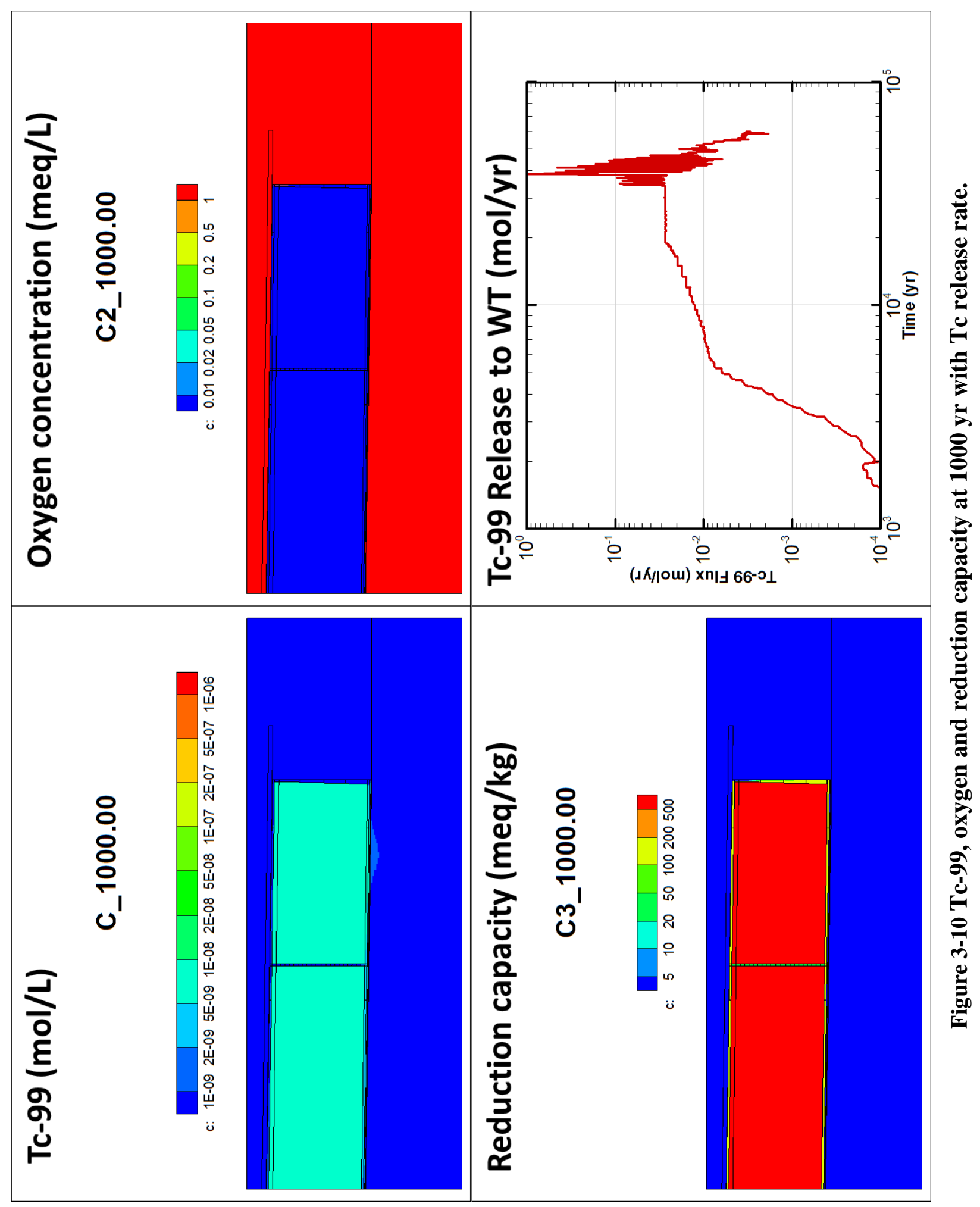




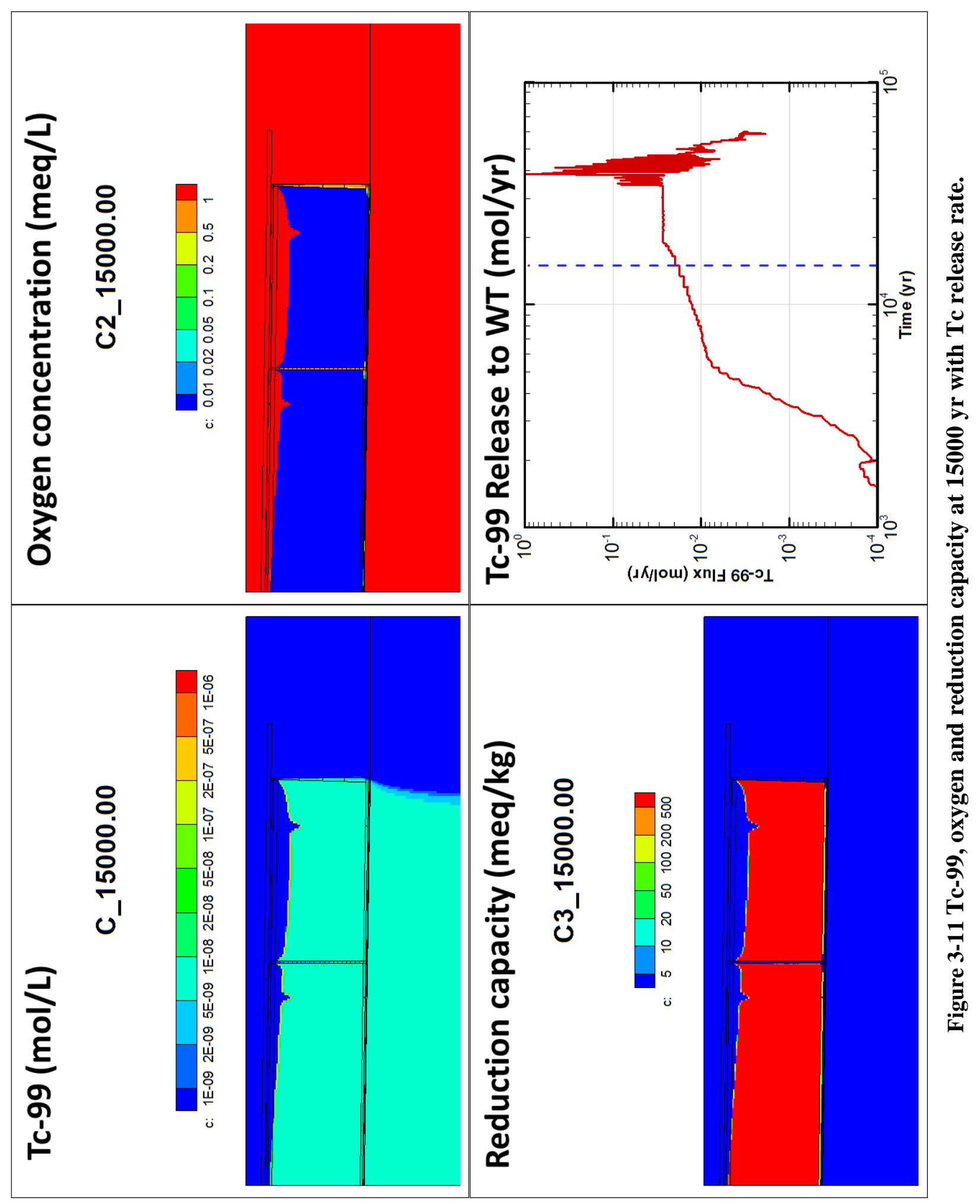




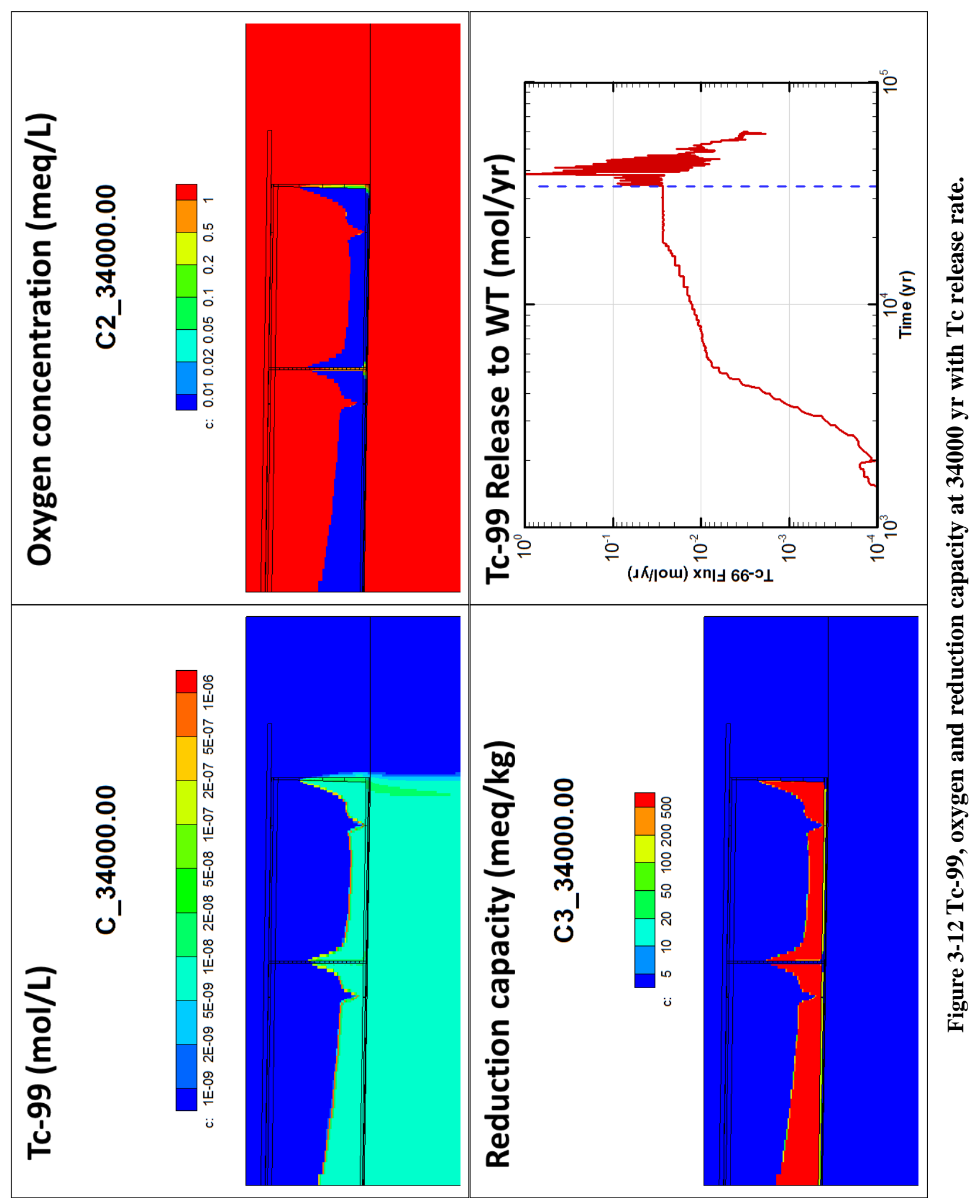




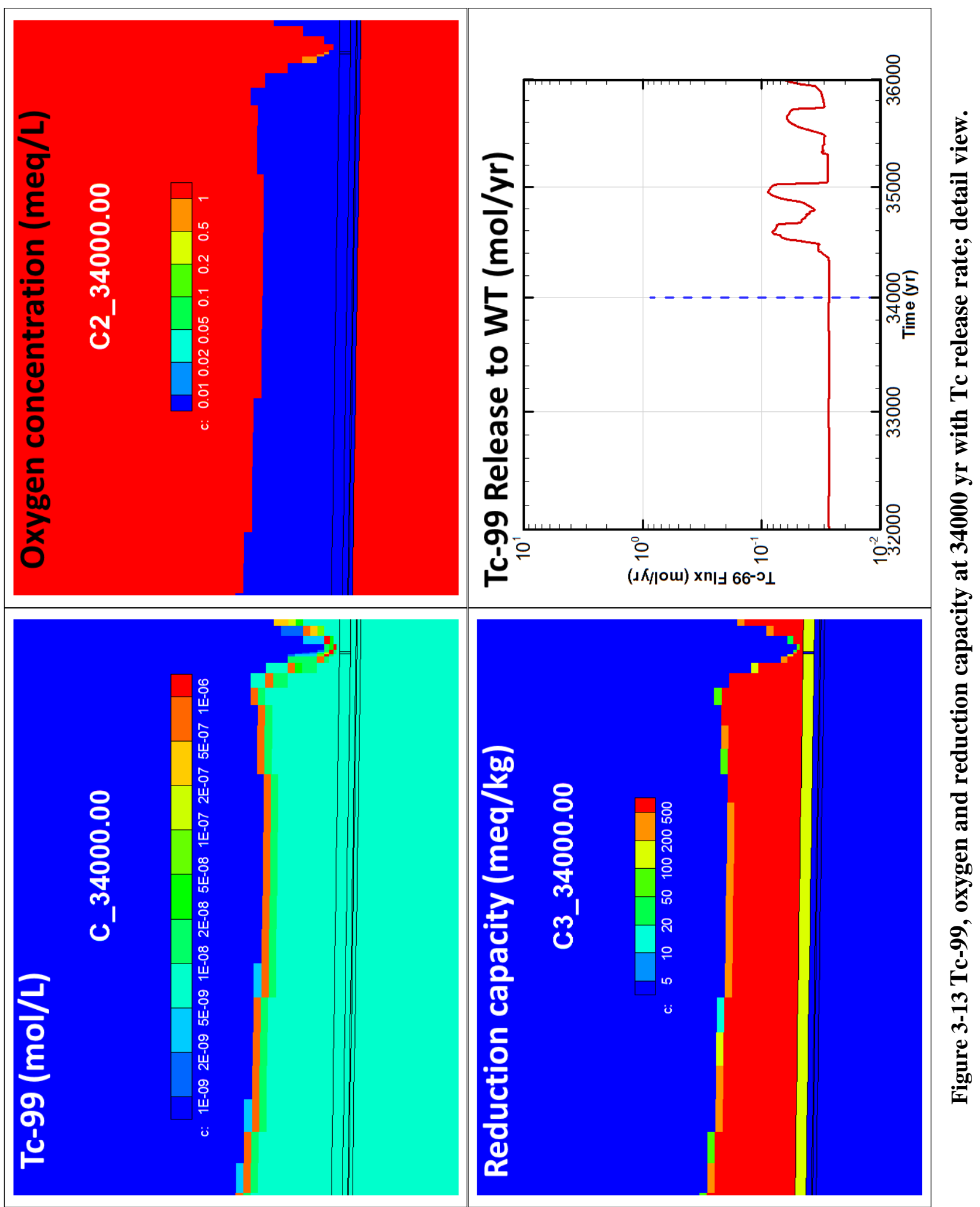




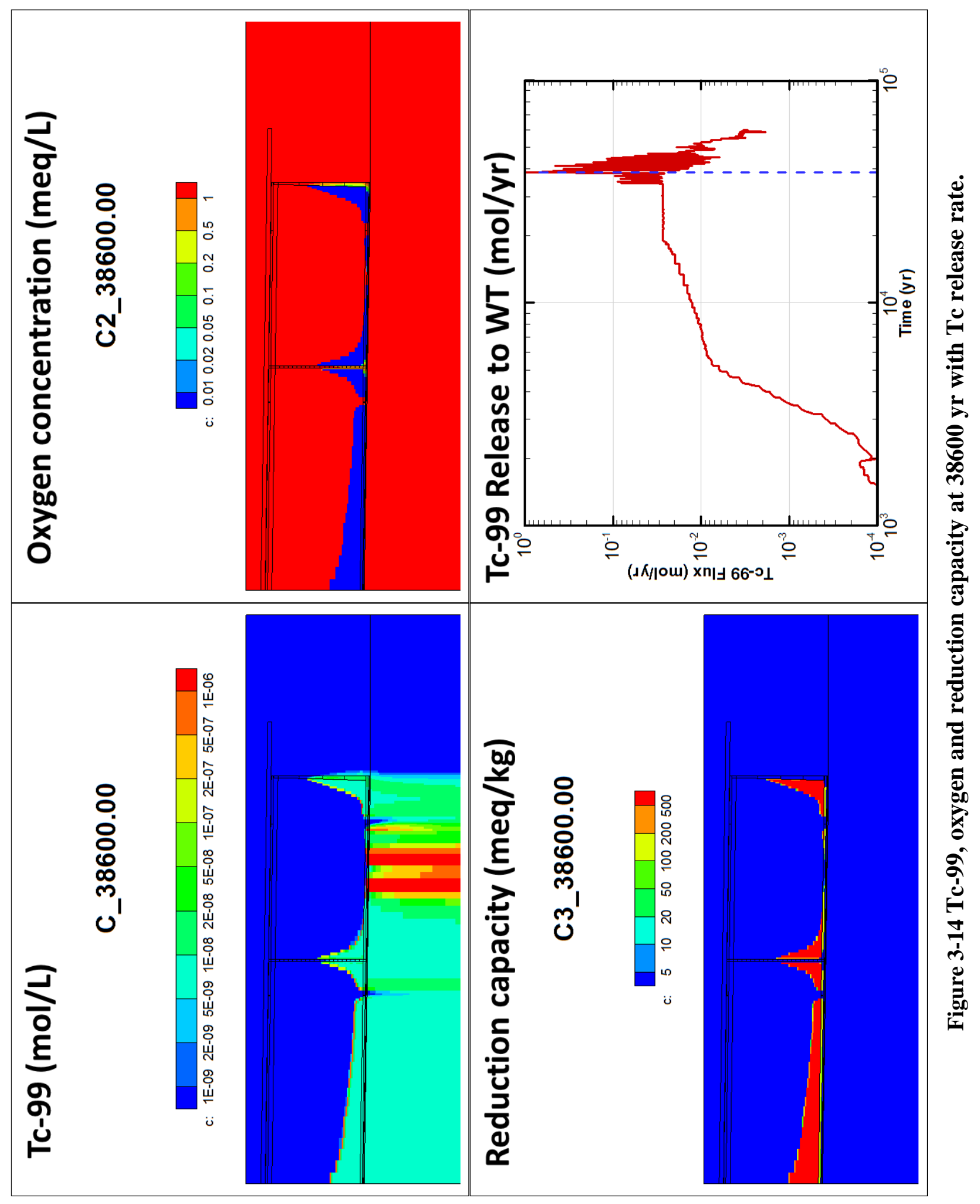




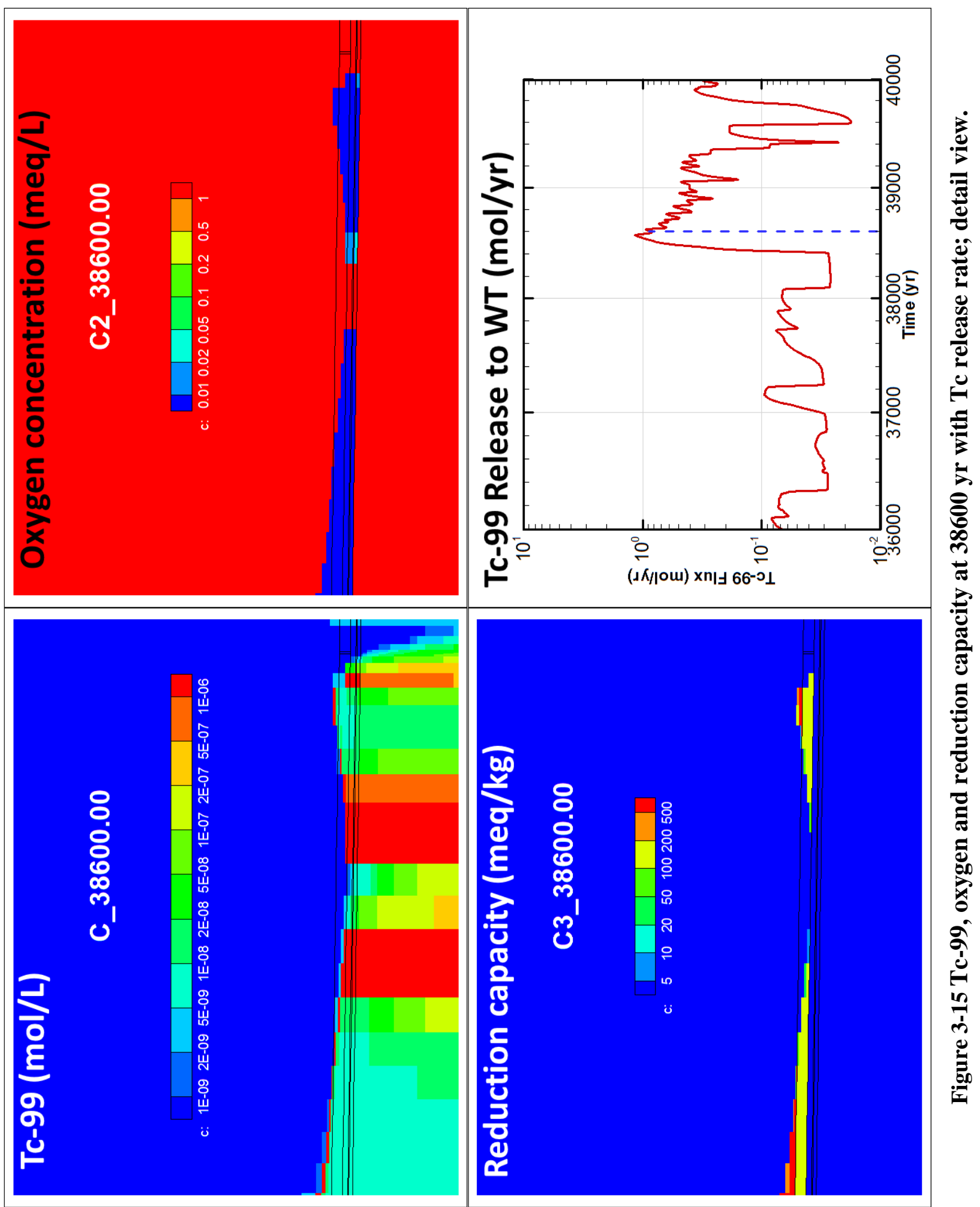




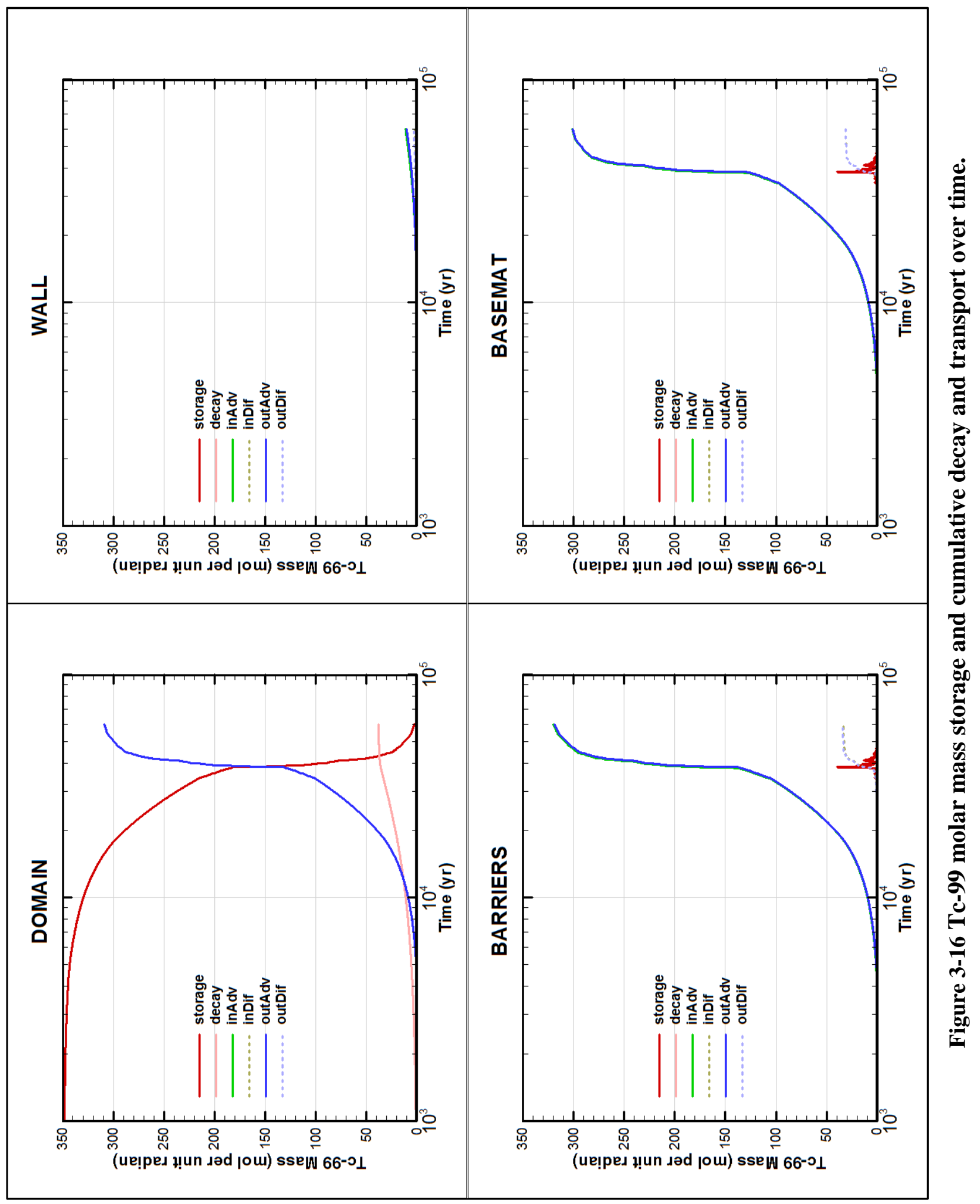




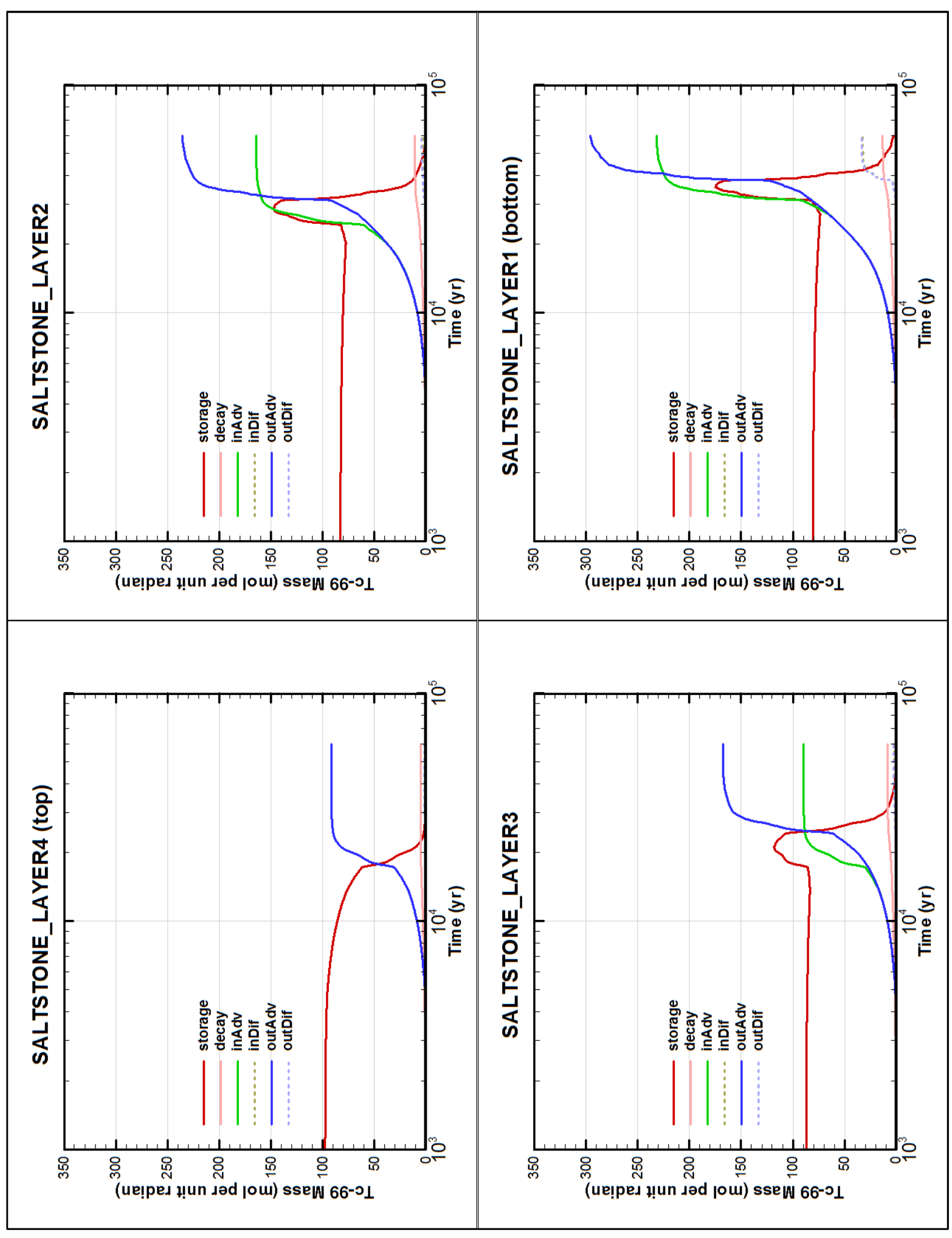

离 


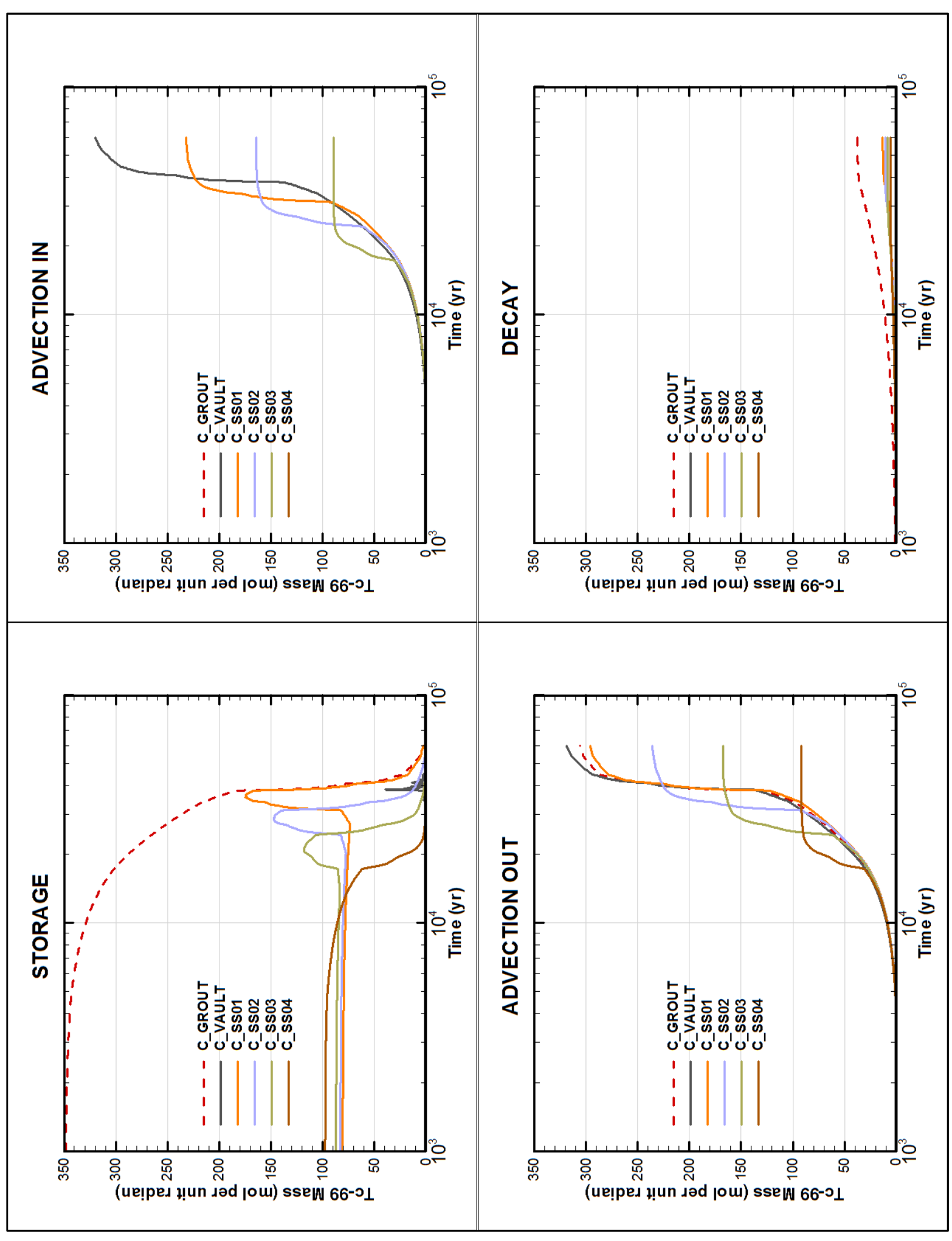

荡 

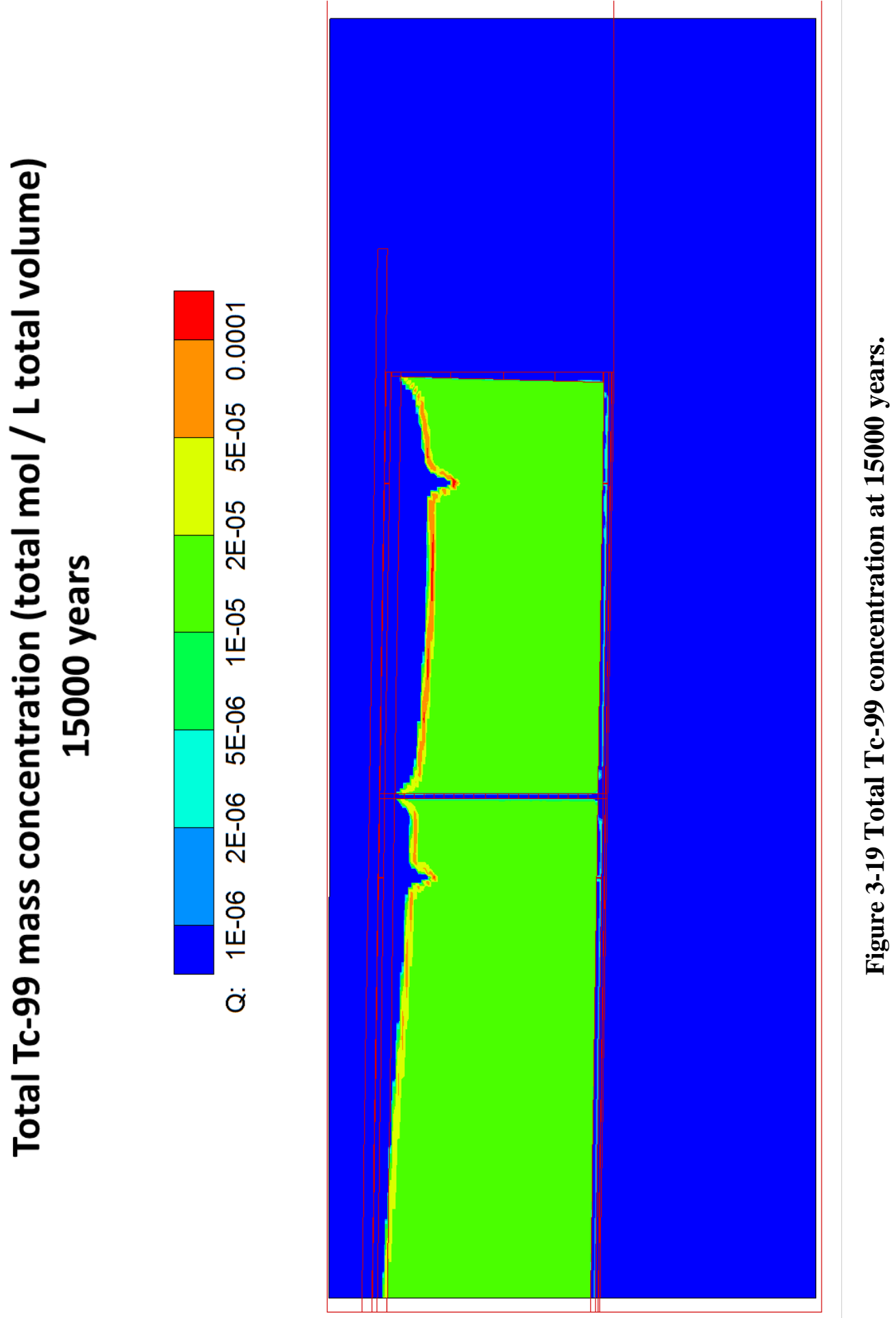

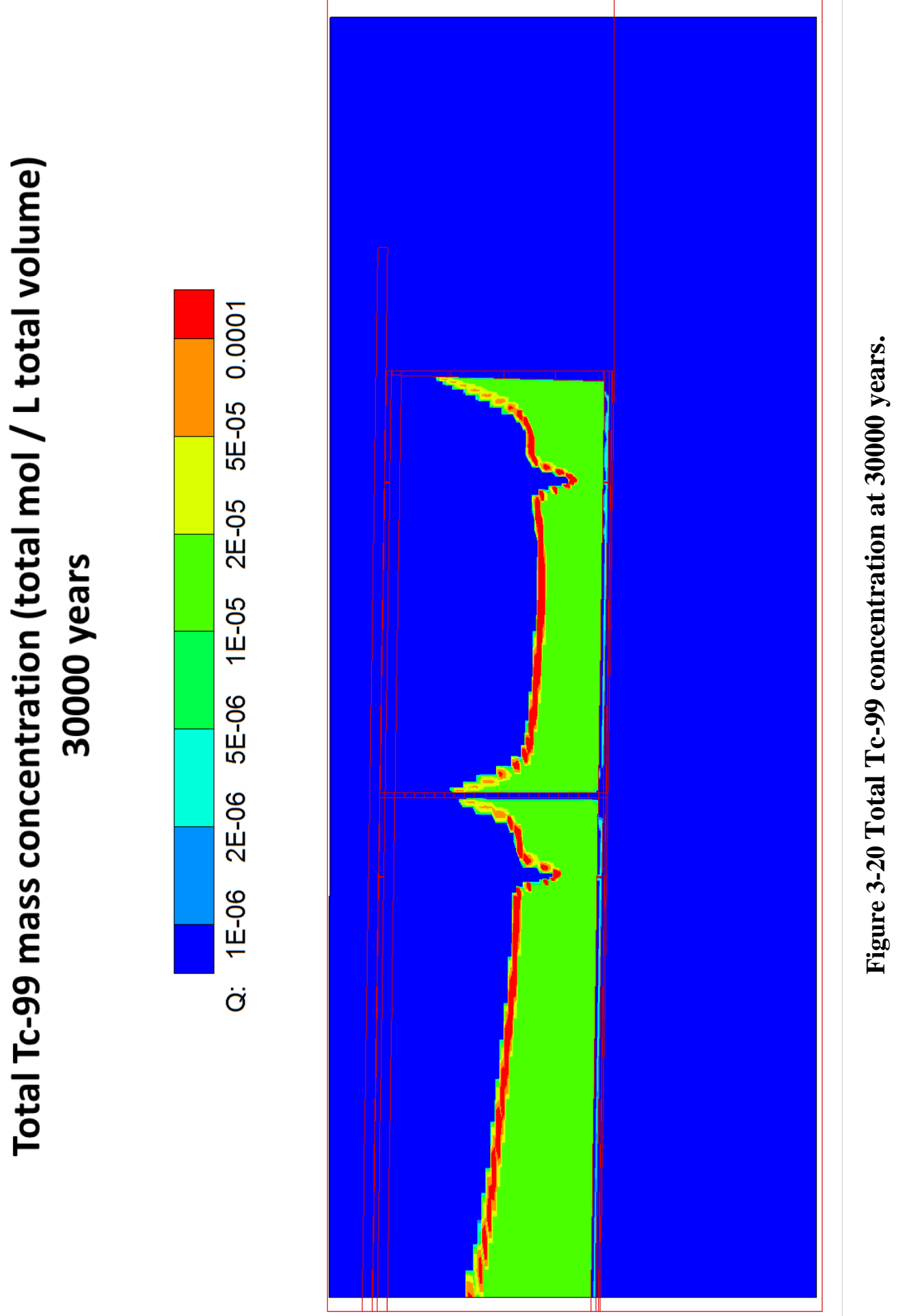


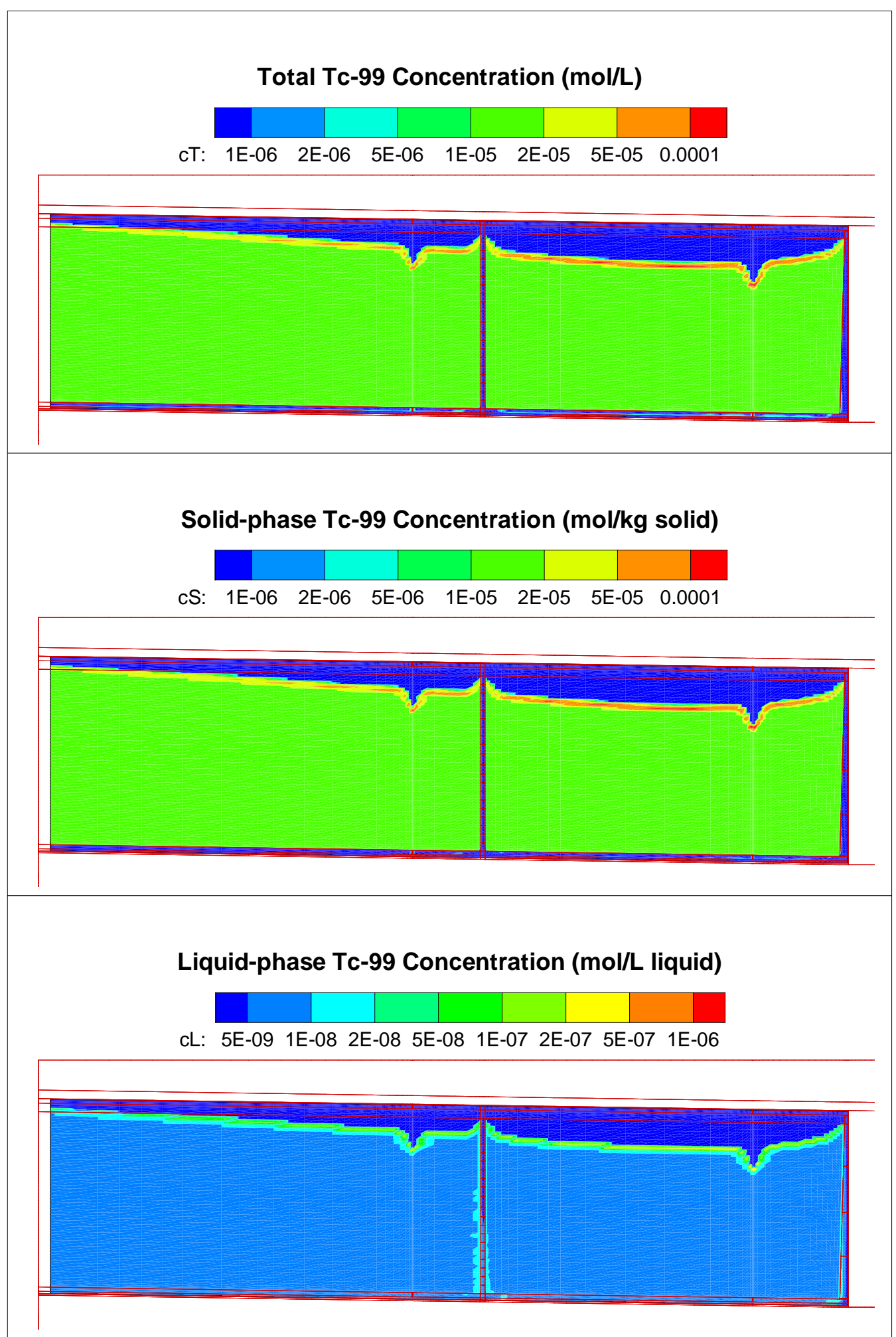

Figure 3-21 Total, solid-phase, and liquid-phase Tc-99 concentrations for SDU 6 cementitious materials at 15000 years. 


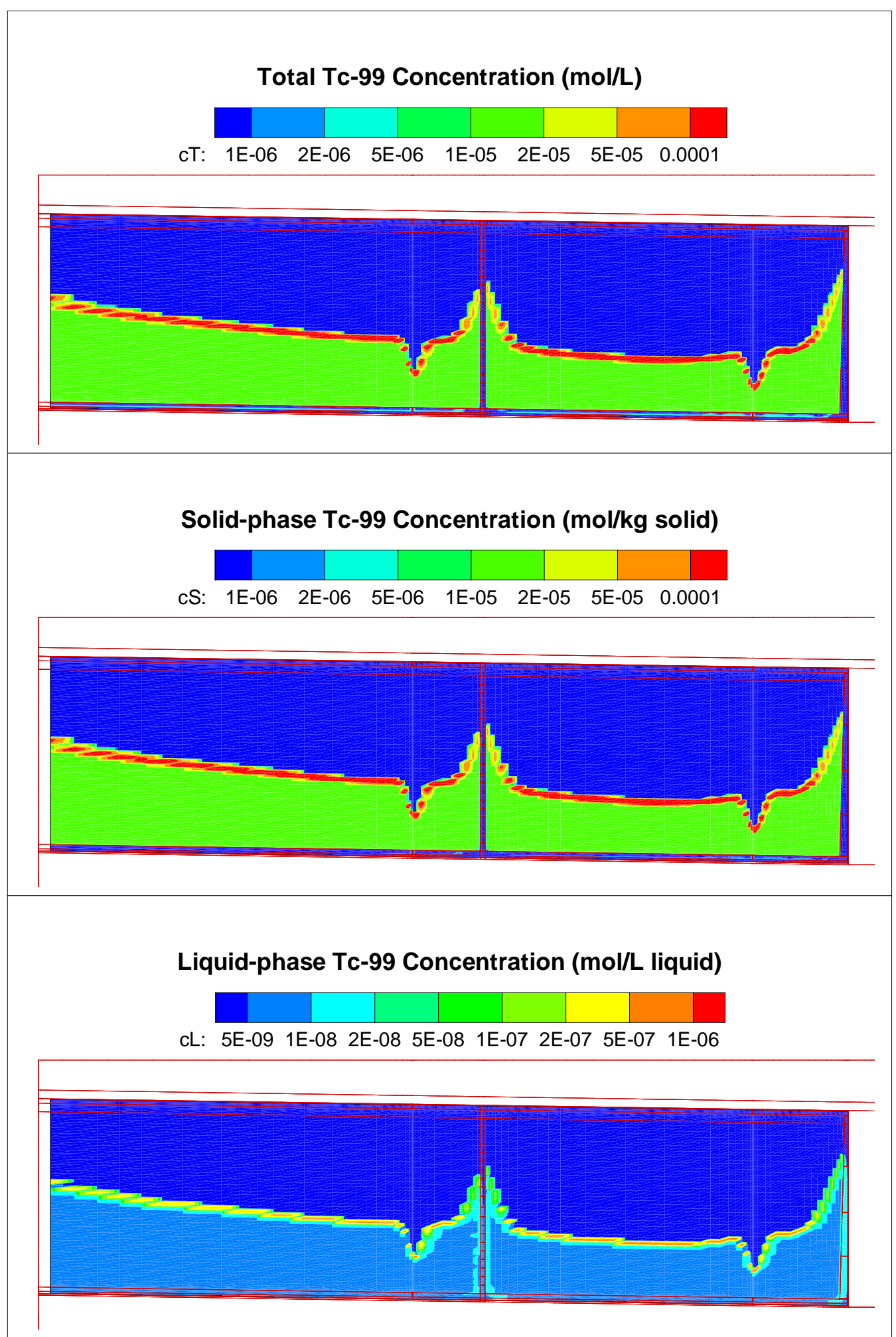

Figure 3-22 Total, solid-phase, and liquid-phase Tc-99 concentrations for SDU 6 cementitious materials at 30000 years. 


\subsection{Flow Field Volumetric Balances and Behavior}

The varying geometry, infiltration, materials, and hydraulic properties of SDUs produce timevarying, multi-dimensional, flow fields. To facilitate insights into vadose zone flow behavior, this section presents volumetric flowrate through time for selected zones within each SDU, example flow field results at simulation year 1000, and a corresponding flow budget for selected zones at 1000 years.

Figure 3-23Figure 3-23 through Figure 3-26Figure 3-26 identify the lateral extent of zones selected for flow rate plots and volumetric flow balances. The lateral extent was chosen to exclude wall concrete, including the inner SDU 4 wall. The selected SDU 1 zones are defined as follows:

"SoilAbove" = soil above the sand drainage layer (and within Figure 3-23 extent)
"SandDrain" = sand drainage layer
"Roof" = roof concrete and column penetration
"CleanGrout" = clean cap grout and column penetration
"Saltstone" = saltstone grout and column penetration
"Floor" = floor concrete, and column and joint penetrations
"SoilBelow" = soil beneath disposal unit

Note that the "Roof" zone does not include the entire roof, and similarly for the "Floor". Also note that the column and joint features are included with the surrounding materials. Zones for SDUs 2, 4, and 6 are similarly defined. For SDUs 2 and 6, the "FloorEtAl" zone includes portions of the floor, upper mudmat, and lower High Density Polyethylene Geosynthetic Clay Liner (HDPE-GCL) (and embedded column and joint features); however, the lower mudmat is included in the "SoilBelowEtAl" zone. The upper HDPE-GCL is treated as a separate zone from the roof, with respect to the volumetric flow rate discussion provided below. Finally, the "CleanGrout" zone defined for SDUs 2 and 6 had been filled with clean grout in prior modeling scenarios, but is filled with contaminated saltstone in the current FY14 Special Analysis simulation (Flach and Taylor 2014). The "CleanGrout" label is retained for consistency with historical modeling simulations and similar zones in SDUs 1 and 4 that remain filled with clean grout.

Figure 3-27 through Figure 3-30 show volumetric flow rate $\left(\mathrm{cm}^{3} / \mathrm{yr}\right)$ through time for the selected grid zones. Also shown in these figures are snapshots of the entire flow field, upper right corner, and lower right corner of the disposal unit at 1000 years. The arrows indicate flow direction but not magnitude. Table 3-1Table 3-1 through Table 3-4Table 3-4 provide numerical flow rate values at 1000 years, broken out by zone surface. The left surface is a no-flow boundary for SDUs 1, 2, and 6 and is omitted from those flow budgets. A positive number indicates upward flow or flow to the right; a negative value indicates downward flow or flow to the left.

Although the predominant flow direction is downward, the sand drainage layer being a notable exception in most time intervals, significant lateral flows are nonetheless present. A portion of the infiltrating water that initially bypasses saltstone via the sand drainage layer (and to a lesser extent the roof) is commonly observed to enter (or re-enter) the engineered structure through the side. As a result, the total flow through engineered system tends to increase moving down the 
disposal unit starting a short distance below the roof. In particular, the "Floor[EtAl]" zones exhibit higher flow than "Saltstone" at 1000 years. Although the net flow through the side of a disposal unit is inward, the velocity is outward for the roof, clean grout layer, and uppermost portion of saltstone. As a result, the flow through clean grout zone is slightly lower than the saltstone zone.

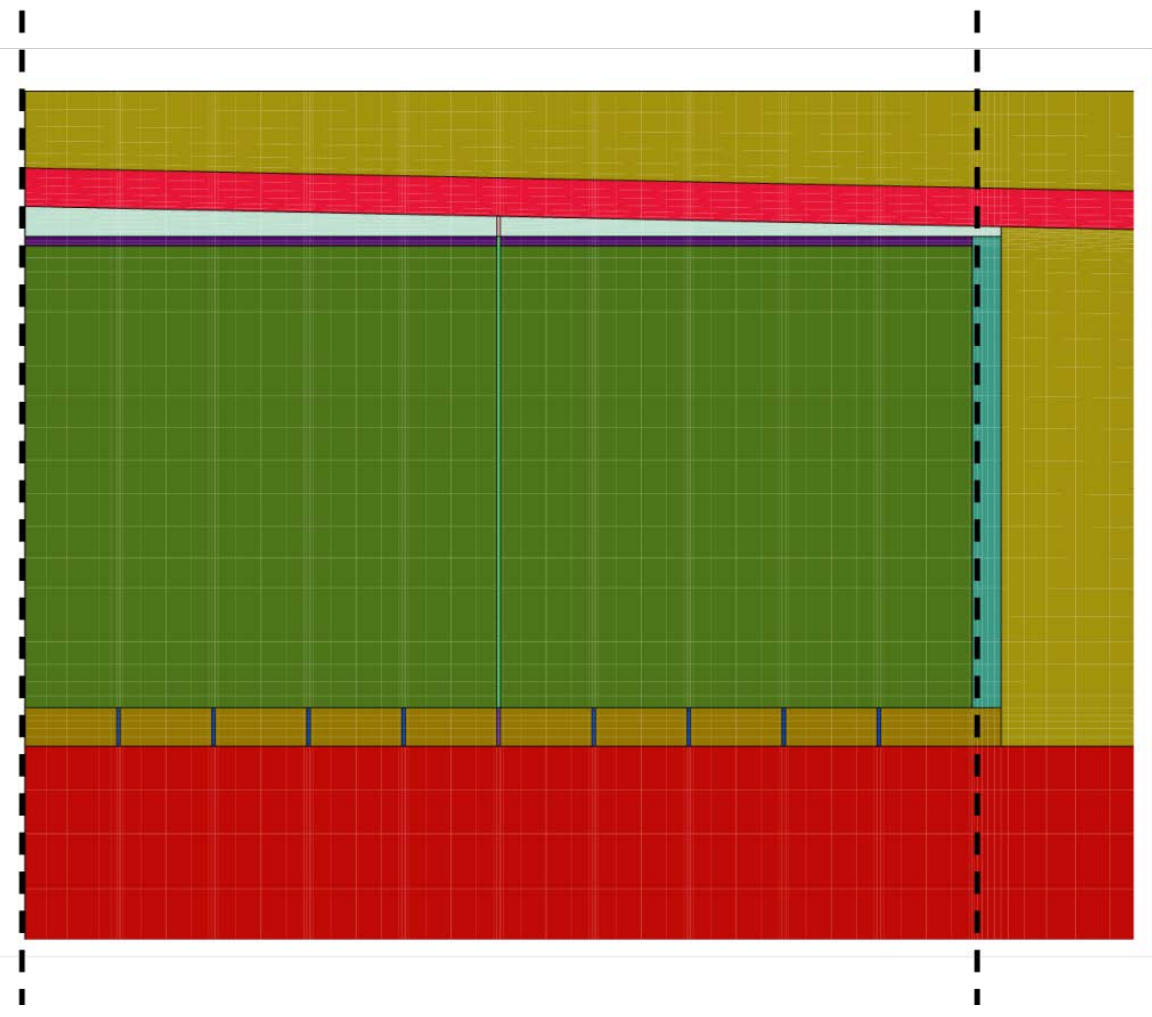

Figure 3-23 Flow balance extent for SDU 1. 


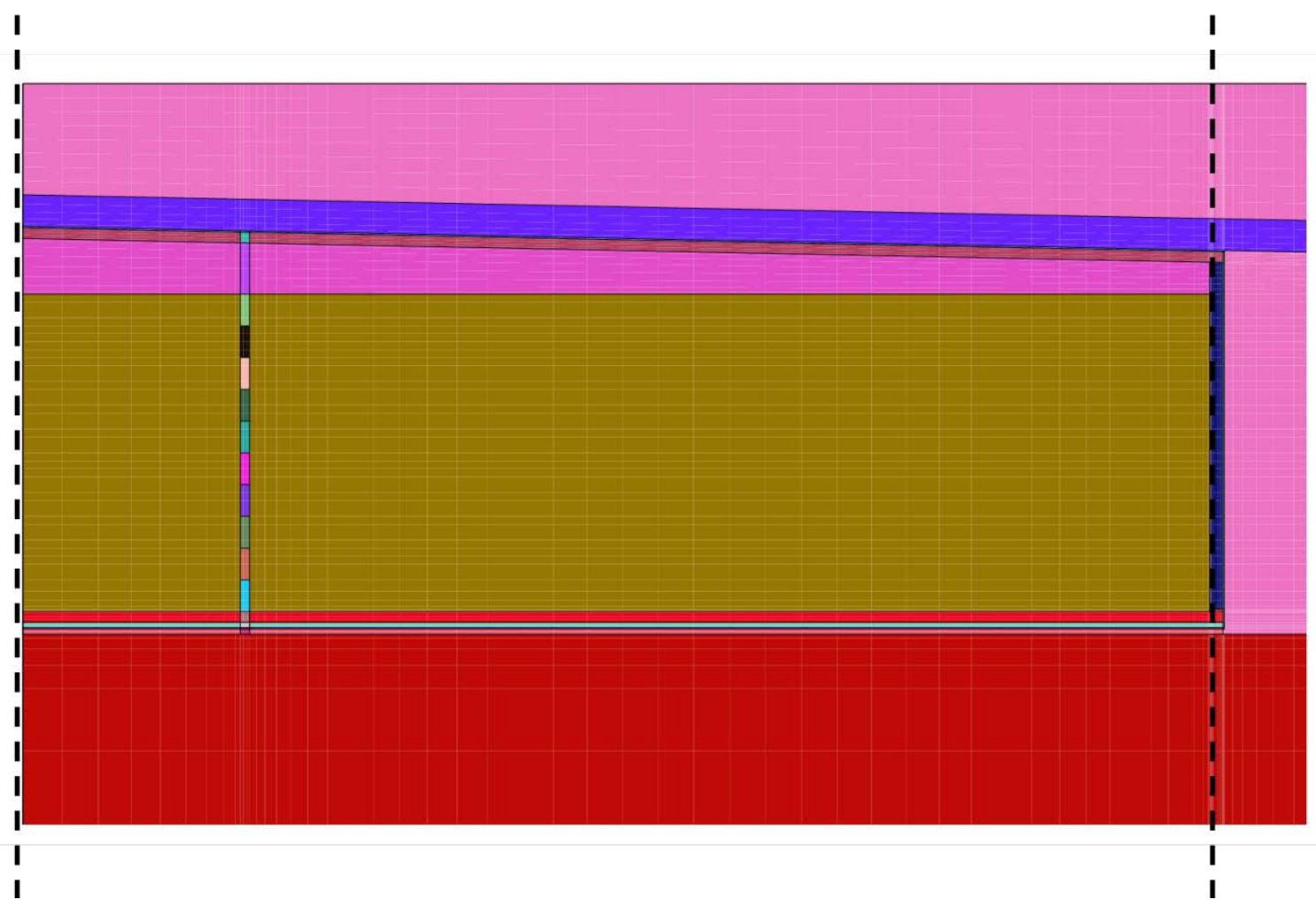

Figure 3-24 Flow balance extent for SDU 2.

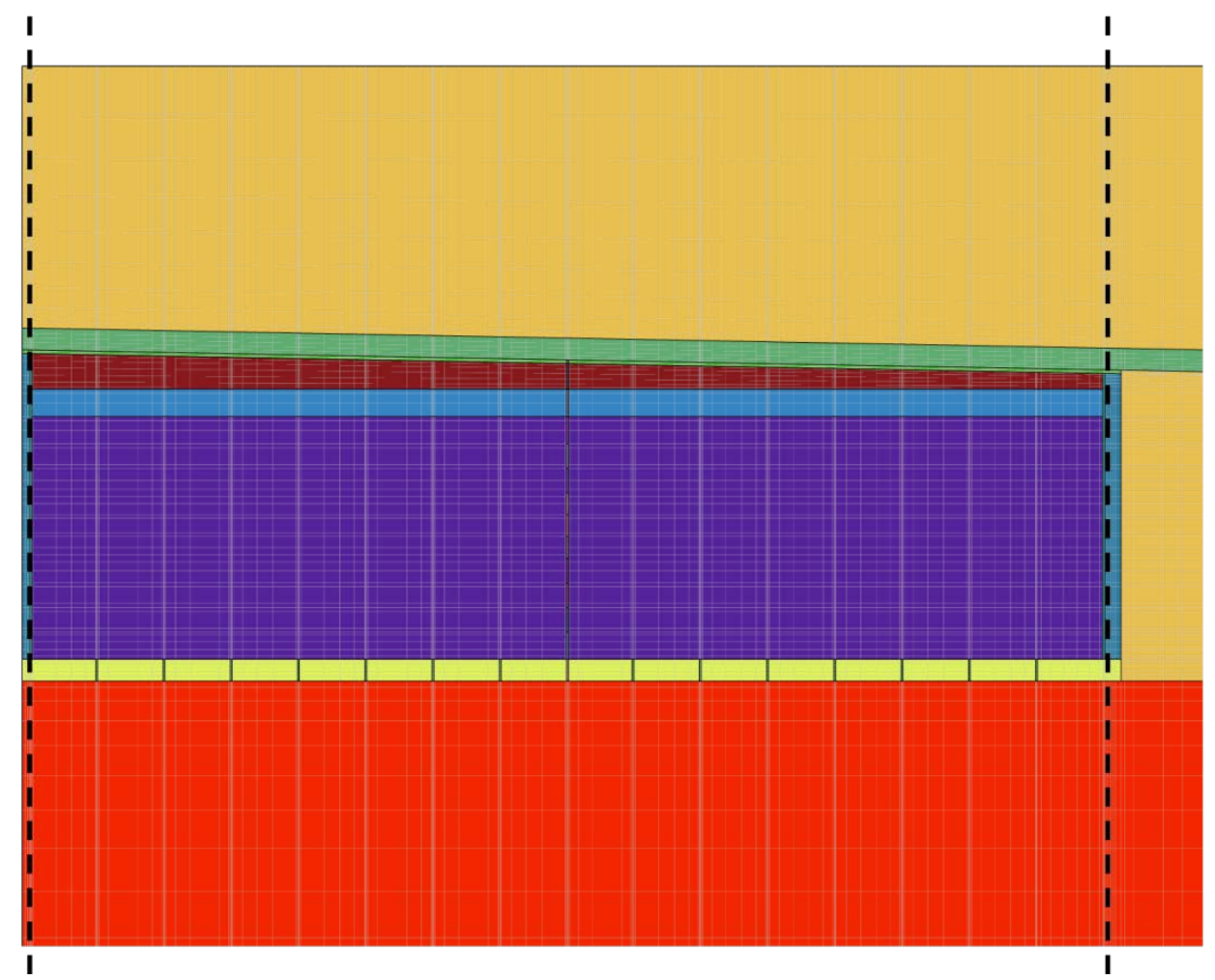

Figure 3-25 Flow balance extent for SDU 4. 


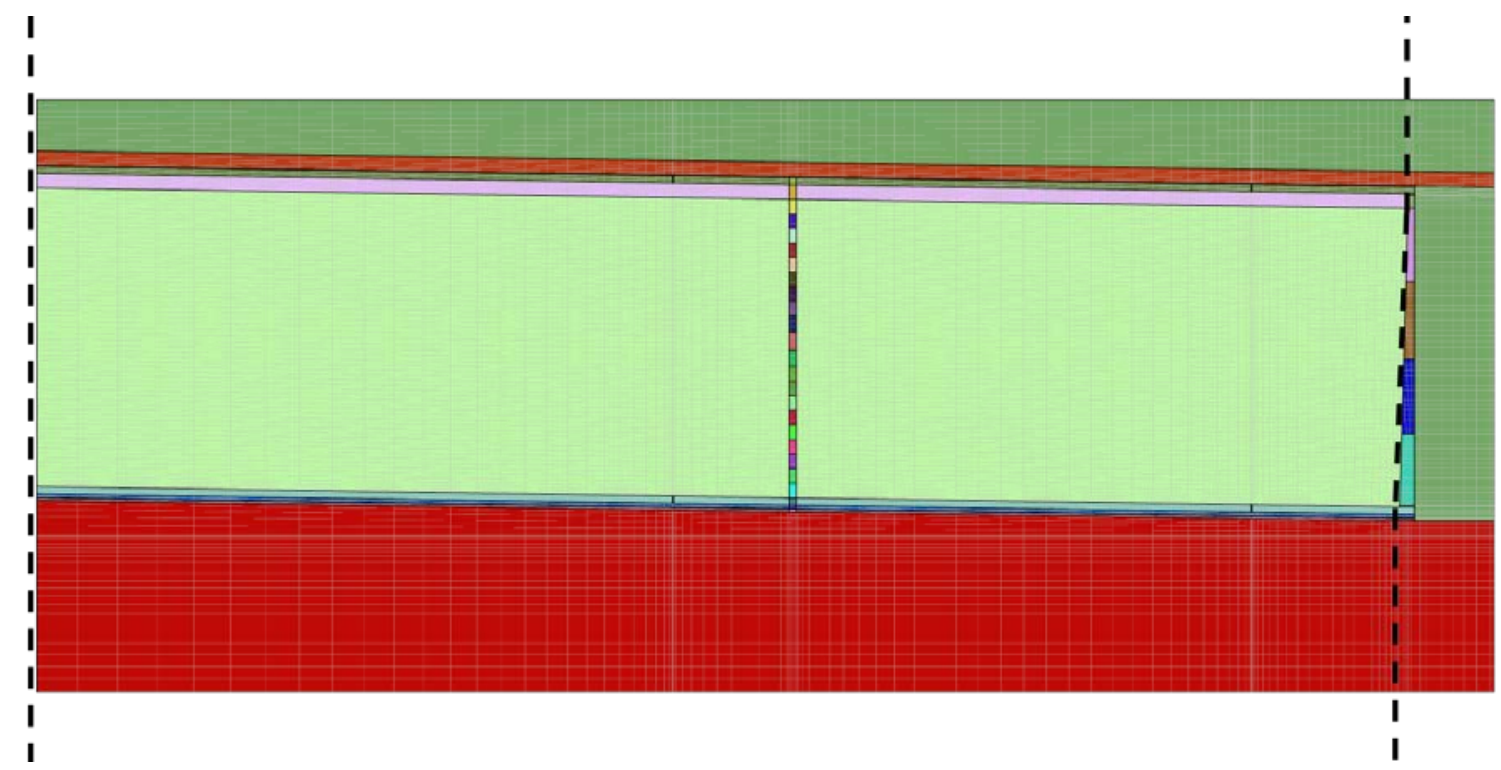

Figure 3-26 Flow balance extent for SDU 6. 


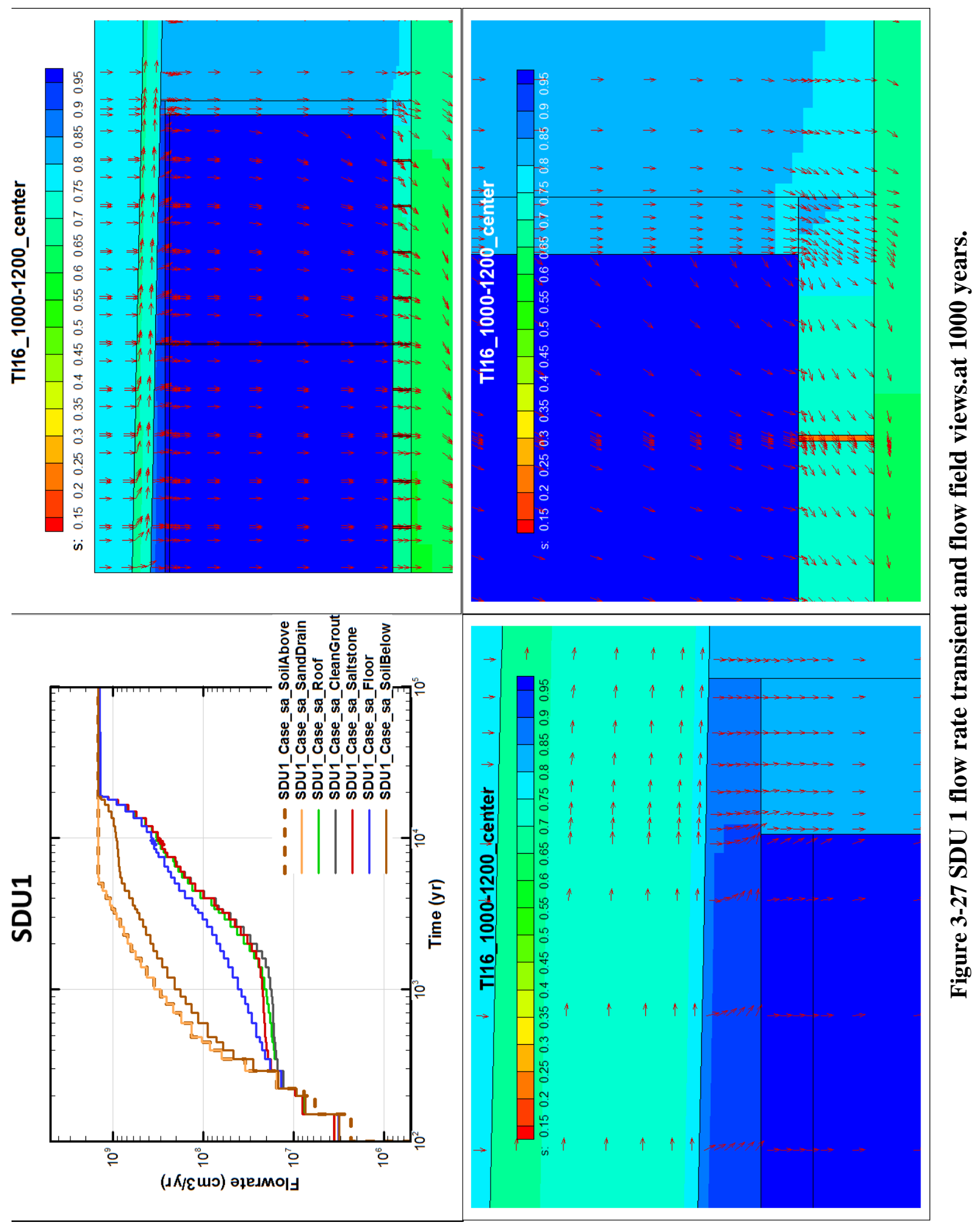




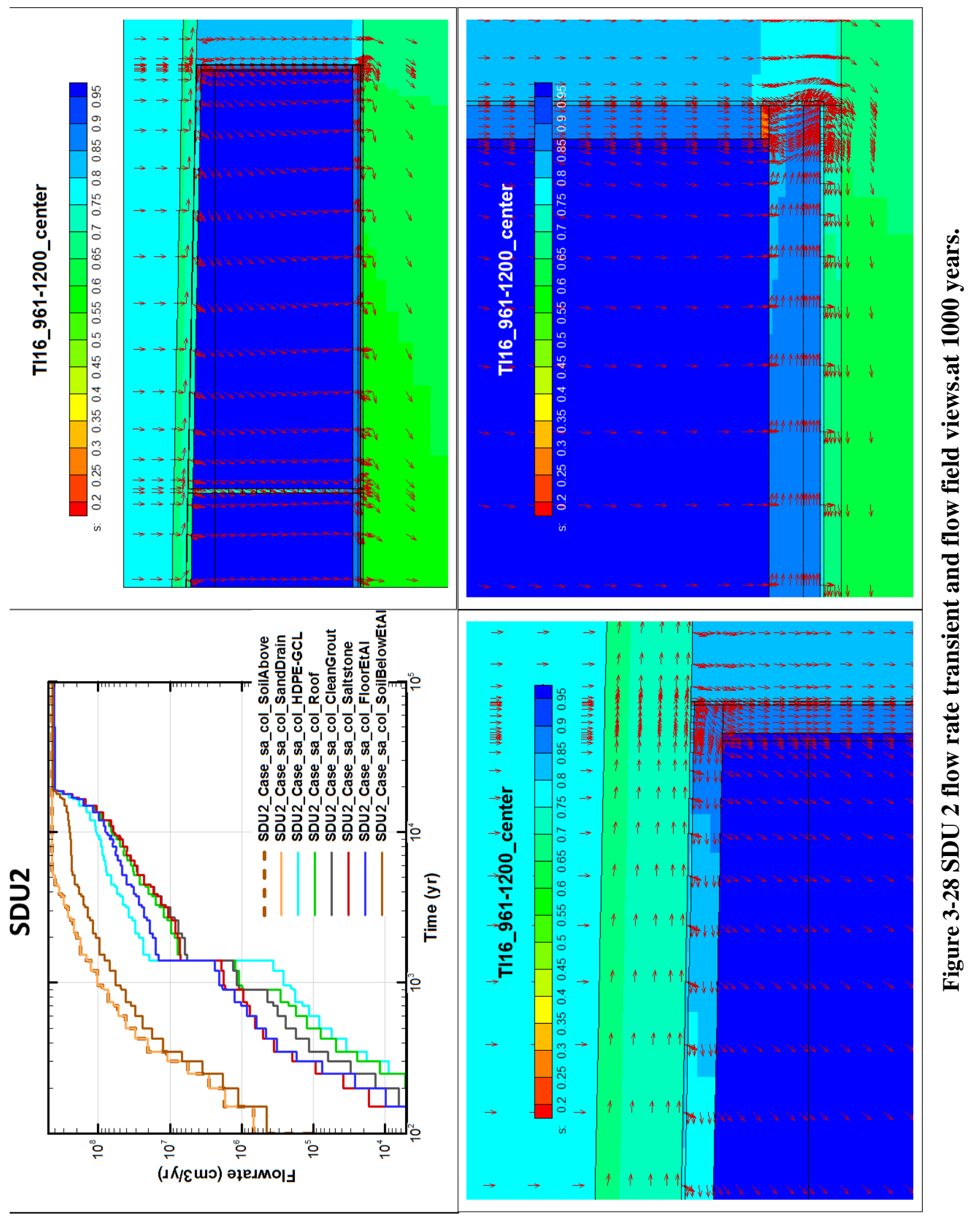



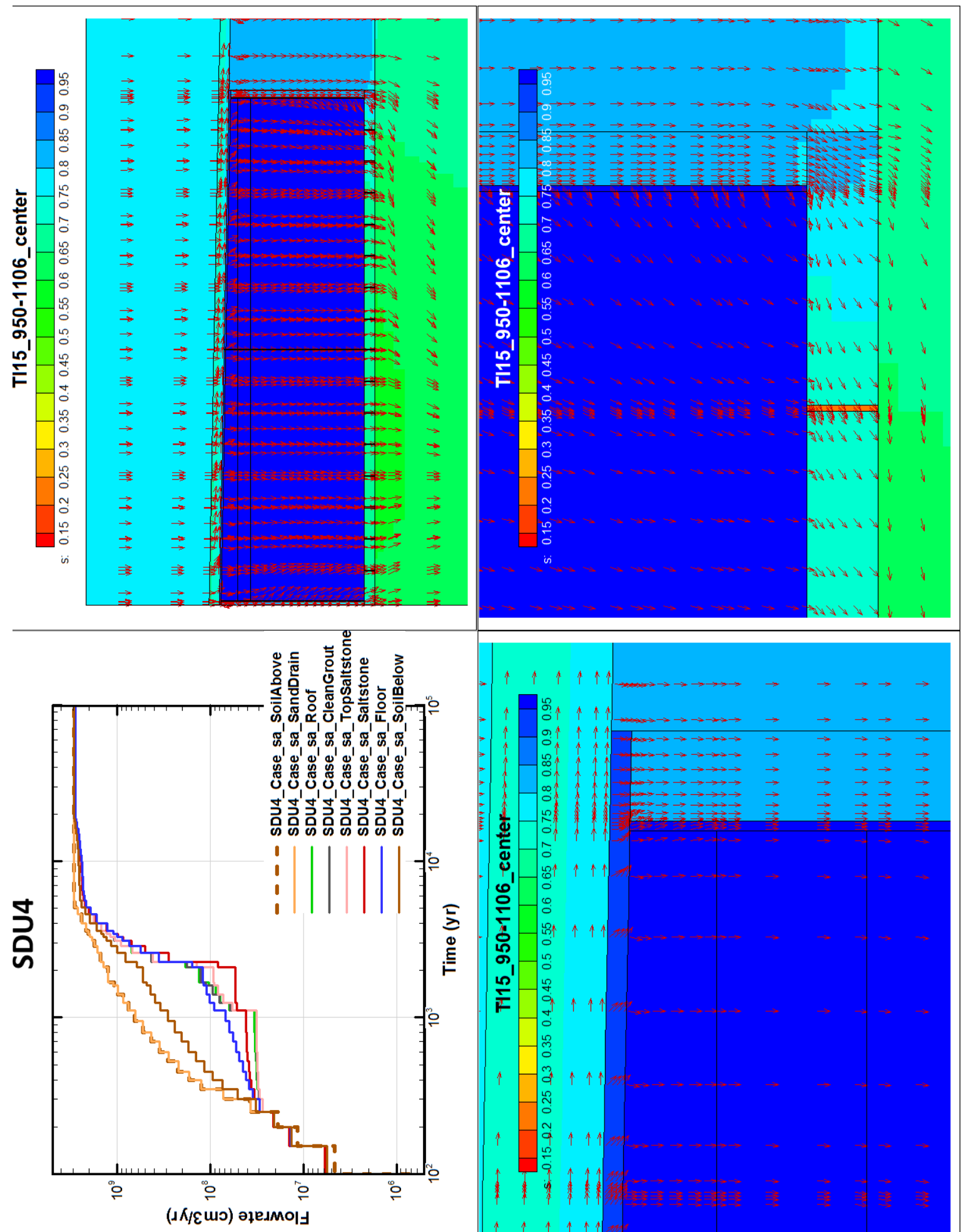

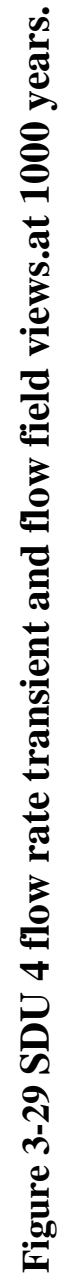




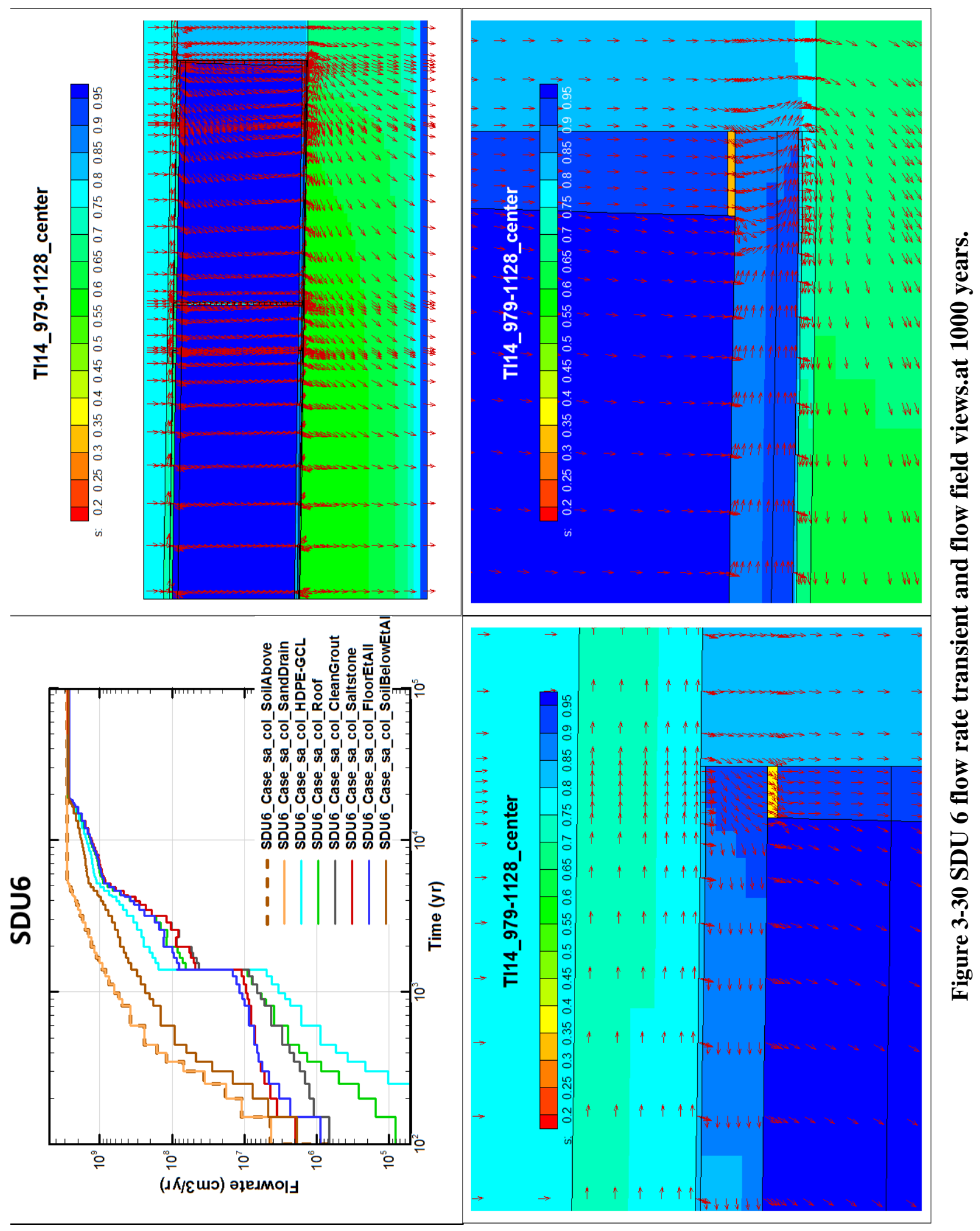


Table 3-1 SDU 1 volumetric flowrate $\left(\mathrm{cm}^{3} / \mathrm{yr}\right)$ at 1000 years.

\begin{tabular}{|c|c|r|}
\hline zone & boundary & flow \\
\hline SoilAbove & Lower & $-9.61 \mathrm{E}+03$ \\
\hline SoilAbove & Upper & $-9.62 \mathrm{E}+03$ \\
\hline SoilAbove & Right & $1.45 \mathrm{E}+01$ \\
\hline SandDrain & Lower & $-5.77 \mathrm{E}+02$ \\
\hline SandDrain & Upper & $-9.61 \mathrm{E}+03$ \\
\hline SandDrain & Right & $9.03 \mathrm{E}+03$ \\
\hline Roof & Lower & $-4.94 \mathrm{E}+02$ \\
\hline Roof & Upper & $-5.77 \mathrm{E}+02$ \\
\hline Roof & Right & $8.35 \mathrm{E}+01$ \\
\hline CleanGrout & Lower & $-4.89 \mathrm{E}+02$ \\
\hline CleanGrout & Upper & $-4.94 \mathrm{E}+02$ \\
\hline CleanGrout & Right & $4.56 \mathrm{E}+00$ \\
\hline Saltstone & Lower & $-6.06 \mathrm{E}+02$ \\
\hline Saltstone & Upper & $-4.89 \mathrm{E}+02$ \\
\hline Saltstone & Right & $-1.17 \mathrm{E}+02$ \\
\hline Floor & Lower & $-1.14 \mathrm{E}+03$ \\
\hline Floor & Upper & $-6.06 \mathrm{E}+02$ \\
\hline Floor & Right & $-5.37 \mathrm{E}+02$ \\
\hline SoilBelow & Lower & $-5.75 \mathrm{E}+03$ \\
\hline SoilBelow & Upper & $-1.14 \mathrm{E}+03$ \\
\hline SoilBelow & Right & $-4.61 \mathrm{E}+03$ \\
\hline
\end{tabular}


Table 3-2 SDU 2 volumetric flowrate $\left(\mathrm{cm}^{3} / \mathrm{yr}\right)$ at 1000 years.

\begin{tabular}{|c|c|c|}
\hline zone & boundary & flow \\
\hline SoilAbove & Lower & $-1.63 \mathrm{E}+07$ \\
\hline SoilAbove & Upper & $-1.63 \mathrm{E}+07$ \\
\hline SoilAbove & Right & $5.63 \mathrm{E}+04$ \\
\hline SandDrain & Lower & $-4.17 \mathrm{E}+04$ \\
\hline SandDrain & Upper & $-1.63 \mathrm{E}+07$ \\
\hline SandDrain & Right & $1.62 \mathrm{E}+07$ \\
\hline HDPE-GCL & Lower & $-4.17 \mathrm{E}+04$ \\
\hline HDPE-GCL & Upper & $-4.17 \mathrm{E}+04$ \\
\hline HDPE-GCL & Right & $-4.79 \mathrm{E}-07$ \\
\hline Roof & Lower & $-1.74 \mathrm{E}+05$ \\
\hline Roof & Upper & $-4.17 \mathrm{E}+04$ \\
\hline Roof & Right & $-1.32 \mathrm{E}+05$ \\
\hline CleanGrout & Lower & $-1.88 \mathrm{E}+05$ \\
\hline CleanGrout & Upper & $-1.74 \mathrm{E}+05$ \\
\hline CleanGrout & Right & $-1.45 \mathrm{E}+04$ \\
\hline Saltstone & Lower & $-2.85 \mathrm{E}+05$ \\
\hline Saltstone & Upper & $-1.88 \mathrm{E}+05$ \\
\hline Saltstone & Right & $-9.70 \mathrm{E}+04$ \\
\hline FloorEtAl & Lower & $-7.78 \mathrm{E}+04$ \\
\hline FloorEtAl & Upper & $-2.85 \mathrm{E}+05$ \\
\hline FloorEtAl & Right & $2.08 \mathrm{E}+05$ \\
\hline SoilBelowEtAl & Lower & $-9.03 \mathrm{E}+06$ \\
\hline SoilBelowEtAl & Upper & $-7.78 \mathrm{E}+04$ \\
\hline SoilBelowEtAl & Right & $-8.95 \mathrm{E}+06$ \\
\hline
\end{tabular}


Table 3-3 SDU 4 volumetric flowrate $\left(\mathrm{cm}^{3} / \mathrm{yr}\right)$ at 1000 years.

\begin{tabular}{|c|c|c|}
\hline zone & boundary & flow \\
\hline SoilAbove & Lower & $-1.77 \mathrm{E}+04$ \\
\hline SoilAbove & Upper & $-1.77 \mathrm{E}+04$ \\
\hline SoilAbove & Left & $8.86 \mathrm{E}+00$ \\
\hline SoilAbove & Right & $8.14 \mathrm{E}+01$ \\
\hline SandDrain & Lower & $-9.31 \mathrm{E}+02$ \\
\hline SandDrain & Upper & $-1.77 \mathrm{E}+04$ \\
\hline SandDrain & Left & $-5.60 \mathrm{E}+01$ \\
\hline SandDrain & Right & $1.67 \mathrm{E}+04$ \\
\hline Roof & Lower & $-8.82 \mathrm{E}+02$ \\
\hline Roof & Upper & $-9.31 \mathrm{E}+02$ \\
\hline Roof & Left & $-1.39 \mathrm{E}+01$ \\
\hline Roof & Right & $3.48 \mathrm{E}+01$ \\
\hline CleanGrout & Lower & $-8.78 \mathrm{E}+02$ \\
\hline CleanGrout & Upper & $-8.82 \mathrm{E}+02$ \\
\hline CleanGrout & Left & $-1.64 \mathrm{E}+00$ \\
\hline CleanGrout & Right & $2.84 \mathrm{E}+00$ \\
\hline TopSaltstone & Lower & $-8.81 \mathrm{E}+02$ \\
\hline TopSaltstone & Upper & $-8.78 \mathrm{E}+02$ \\
\hline TopSaltstone & Left & $3.87 \mathrm{E}+00$ \\
\hline TopSaltstone & Right & $2.48 \mathrm{E}-01$ \\
\hline Saltstone & Lower & $-1.13 \mathrm{E}+03$ \\
\hline Saltstone & Upper & $-8.81 \mathrm{E}+02$ \\
\hline Saltstone & Left & $1.37 \mathrm{E}+02$ \\
\hline Saltstone & Right & $-1.16 \mathrm{E}+02$ \\
\hline Floor & Lower & $-1.90 \mathrm{E}+03$ \\
\hline Floor & Upper & $-1.13 \mathrm{E}+03$ \\
\hline Floor & Left & $4.02 \mathrm{E}+01$ \\
\hline Floor & Right & $-7.22 \mathrm{E}+02$ \\
\hline SoilBelow & Lower & $-7.87 \mathrm{E}+03$ \\
\hline SoilBelow & Upper & $-1.90 \mathrm{E}+03$ \\
\hline SoilBelow & Left & $2.94 \mathrm{E}+01$ \\
\hline SoilBelow & Right & $-5.94 \mathrm{E}+03$ \\
\hline
\end{tabular}


SRNL-STI-2014-00505

Revision 0

Table 3-4 SDU 6 volumetric flowrate $\left(\mathrm{cm}^{3} / \mathrm{yr}\right)$ at 1000 years.

\begin{tabular}{|c|c|c|}
\hline zone & boundary & flow \\
\hline SoilAbove & Lower & $-1.01 \mathrm{E}+08$ \\
\hline SoilAbove & Upper & $-1.01 \mathrm{E}+08$ \\
\hline SoilAbove & Right & $1.50 \mathrm{E}+05$ \\
\hline SandDrain & Lower & $-5.33 \mathrm{E}+05$ \\
\hline SandDrain & Upper & $-1.01 \mathrm{E}+08$ \\
\hline SandDrain & Right & $1.00 \mathrm{E}+08$ \\
\hline HDPE-GCL & Lower & $-5.33 \mathrm{E}+05$ \\
\hline HDPE-GCL & Upper & $-5.33 \mathrm{E}+05$ \\
\hline HDPE-GCL & Right & $-2.11 \mathrm{E}-06$ \\
\hline Roof & Lower & $-1.03 \mathrm{E}+06$ \\
\hline Roof & Upper & $-5.33 \mathrm{E}+05$ \\
\hline Roof & Right & $-4.99 \mathrm{E}+05$ \\
\hline CleanGrout & Lower & $-1.06 \mathrm{E}+06$ \\
\hline CleanGrout & Upper & $-1.03 \mathrm{E}+06$ \\
\hline CleanGrout & Right & $-2.91 \mathrm{E}+04$ \\
\hline Saltstone & Lower & $-1.52 \mathrm{E}+06$ \\
\hline Saltstone & Upper & $-1.06 \mathrm{E}+06$ \\
\hline Saltstone & Right & $-4.60 \mathrm{E}+05$ \\
\hline FloorEtAll & Lower & $-7.84 \mathrm{E}+05$ \\
\hline FloorEtAll & Upper & $-1.52 \mathrm{E}+06$ \\
\hline FloorEtAll & Right & $7.37 \mathrm{E}+05$ \\
\hline SoilBelowEtAl & Lower & $-3.72 \mathrm{E}+07$ \\
\hline SoilBelowEtAl & Upper & $-7.84 \mathrm{E}+05$ \\
\hline SoilBelowEtAl & Right & $-3.64 \mathrm{E}+07$ \\
\hline
\end{tabular}

\subsection{Simulation Results}

Figure 4-1 and Figure 4-2 for SDU6 show examples of the effect of the modeling changes. "SA_Col" denotes the current analyses while "SA" denotes the previous analyses. Timings of local fluxes change somewhat, but the global peak remains essentially the same for I-129. The "SA" run for Tc-99 was only run to 50,000 years. The change in the column degradation model allowed for more Tc-99 to be released earlier in the simulation which in turn led to lower peaks later in the simulation. 


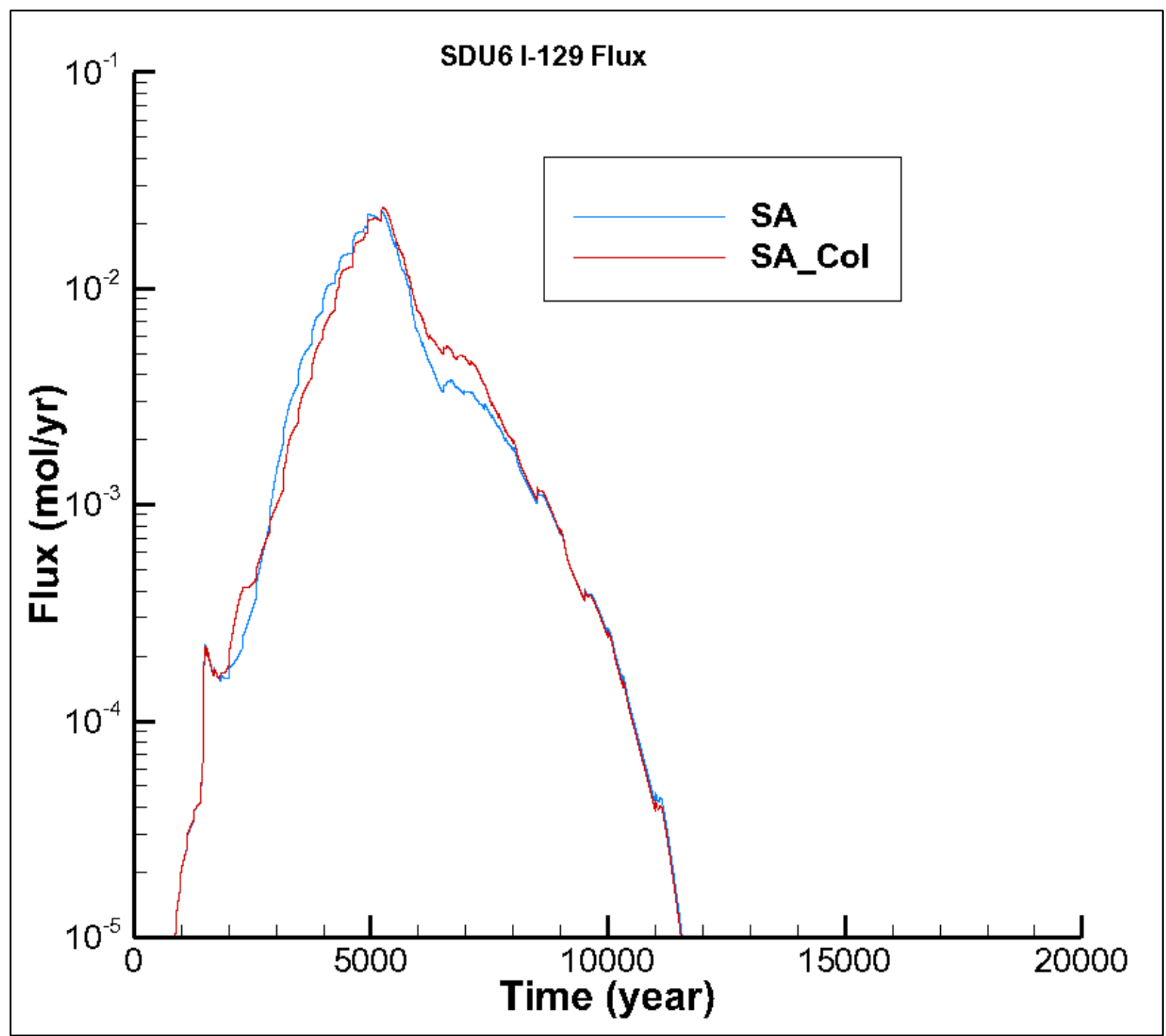

Figure 4-1 Comparison of SDU 6 I-129 Fluxes 


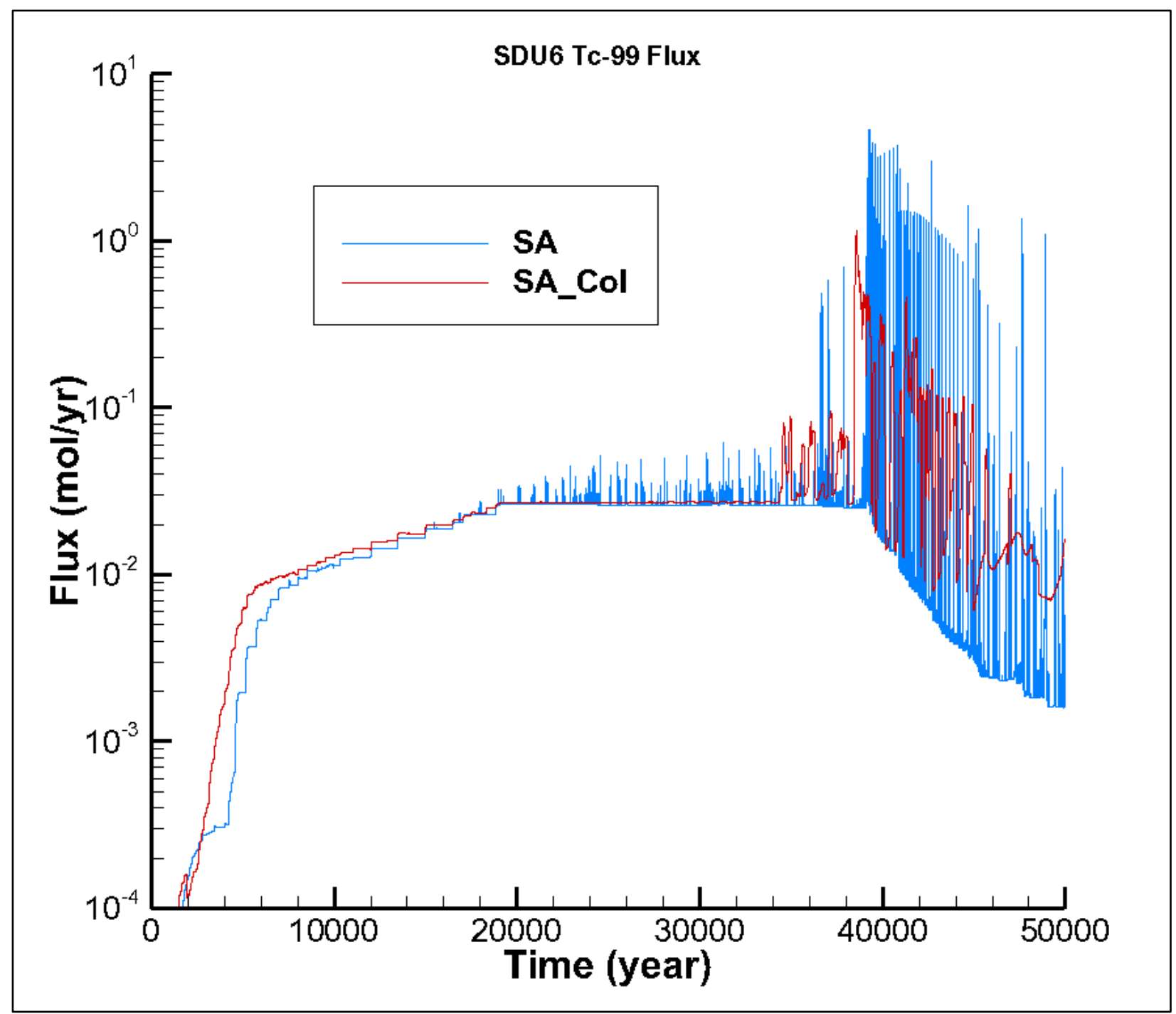

Figure 4-2 Comparison of SDU 6 Tc-99 Fluxes

Figure 4-3 and Figure 4-4 show SDU2 comparisons of I-129 fluxes and Tc-99 fluxes between the two cases. Very slight variations can be seen between the two cases for either radionuclide. 


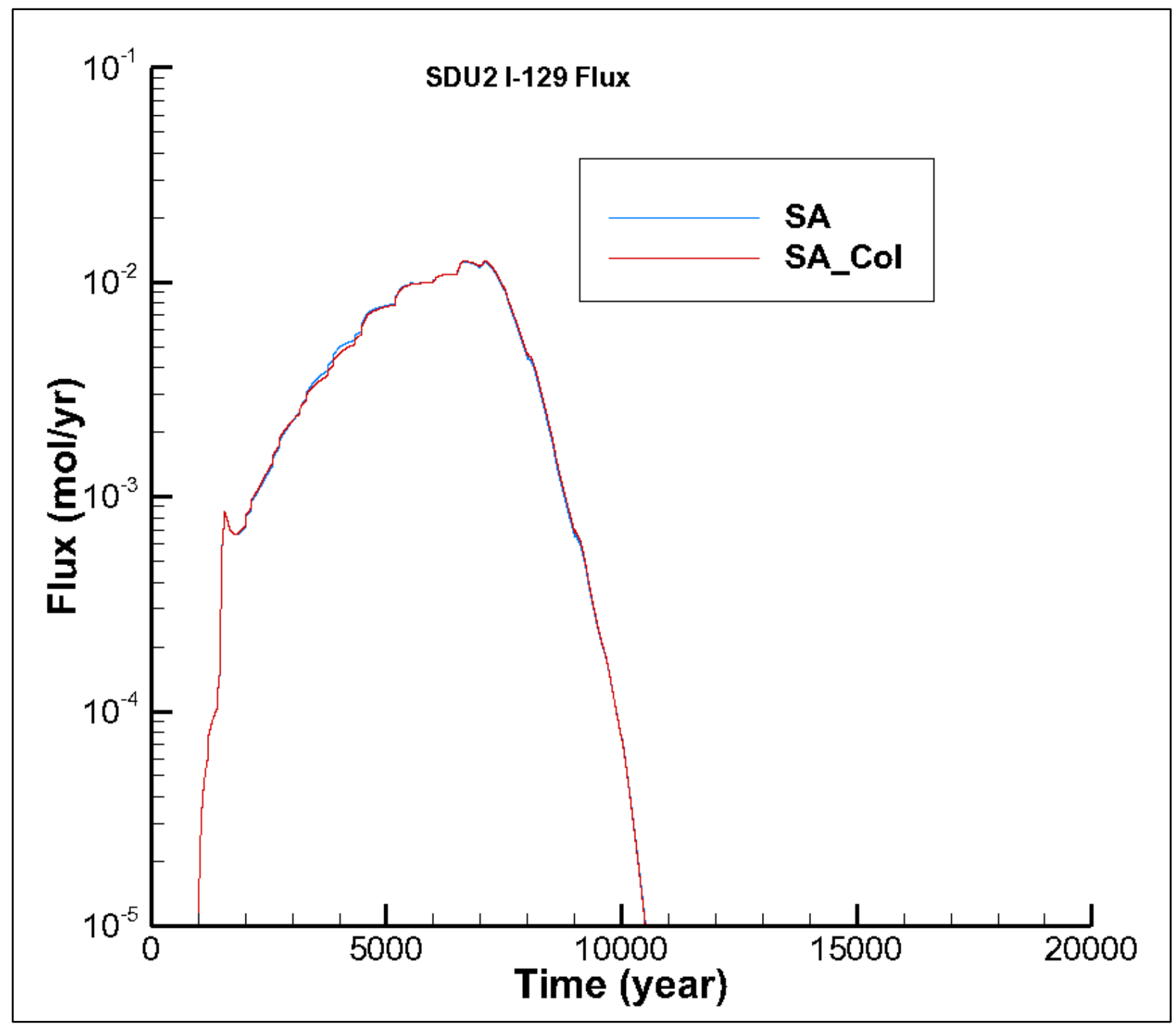

Figure 4-3 Comparison of SDU2 I-129 Fluxes 


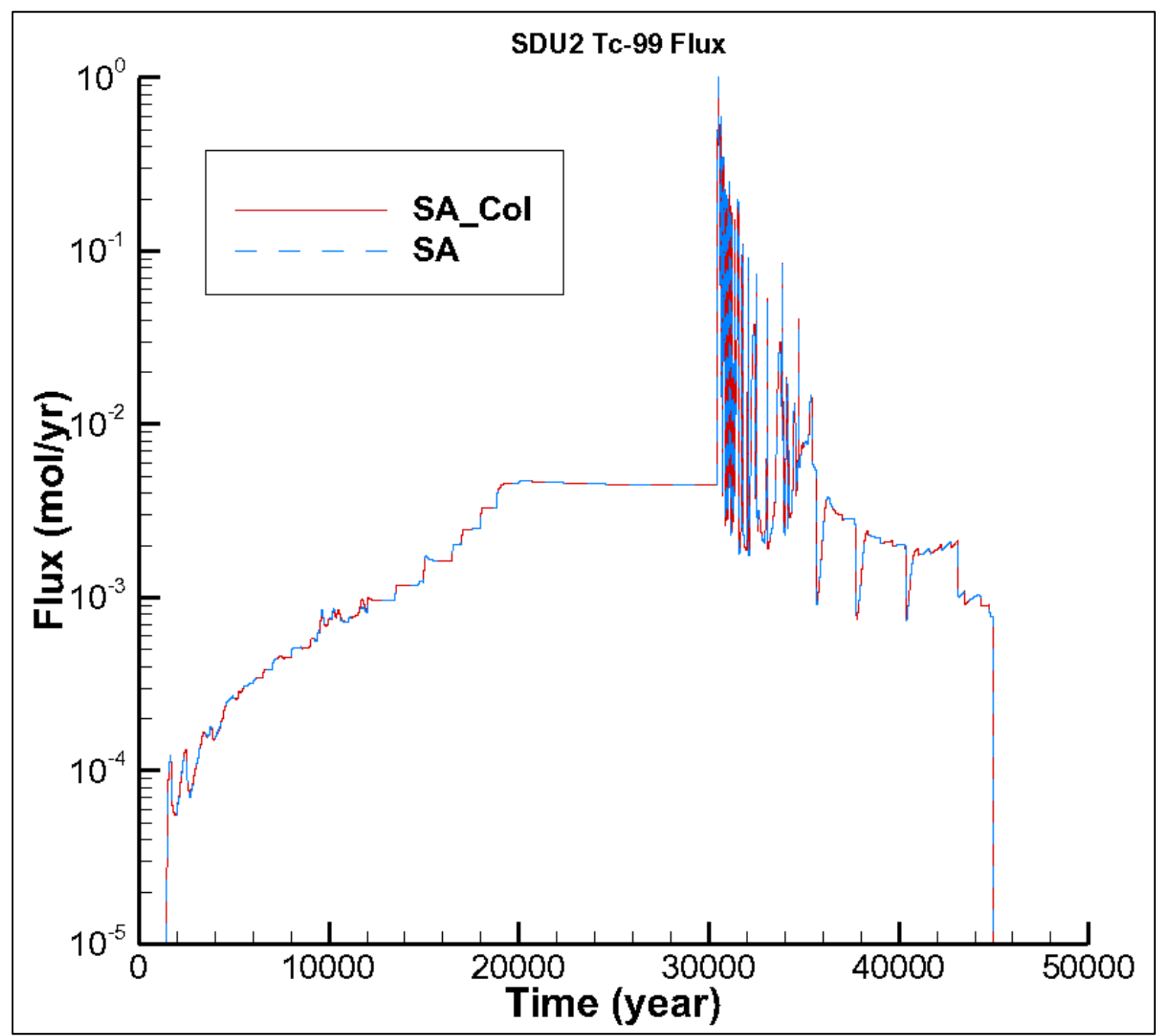

Figure 4-4 Comparison of SDU2 Tc-99 Fluxes

\subsection{References}

Flach, G. P. and G. A. Taylor, PORFLOW Modeling Supporting the FY14 Saltstone Special Analysis, SRNL-STI-2014-00083, Rev. 1, April 2014.

Flach, G. P. and Smith III, F., G., Degradation of Cementitious Materials Associated with Saltstone Disposal Units, SRNL-STI-2013-00118, Rev. 2, September 2014.

Kaplan, D. I. and D. Li, Solubility of Technetium Dioxides $\left(\mathrm{TcO}_{2}-\mathrm{C}, \mathrm{TcO}_{2} \cdot 1.6 \mathrm{H}_{2} \mathrm{O}\right.$ and $\mathrm{TcO}_{2} \cdot 2 \mathrm{H}_{2} \mathrm{O}$ ) in Reducing Cementitious Material Leachates: A Thermodynamic Calculation, SRNL-STI-2012-00769, Rev. 1, February 2013. 
Rosenberger, K. H., Sensitivity Analysis for Saltstone Disposal Unit Column Degradation Analyses, G-TTR-Z-00007, Rev. 0, August 2014.

Taylor, G. A., Task Technical and Quality Assurance Plan for Sensitivity analysis for Saltstone Disposal Unit Column Degradation Analyses, SRNL-RP-2014-00868, Rev. 0, August 2014. 
SRNL-STI-2014-00505

Revision 0

This page intentionally left blank 


\section{Distribution:}

R. S. Aylward, 773-42A

B. T. Butcher, 773-43A

S. L. Marra, 773-A

D. A. Crowley, 773-43A

E. N. Hoffman, 999-W

G. P. Flach, 773-42A

K. H. Rosenberger, 705-1C

F. G. Smith, III 703-41A

M. Layton, 705-1C

G. A. Taylor, 773-43A

S. Hommel, 705-1C

Records Administration (EDWS)

S. P. Simner, 705-1C

P. R. Jackson, DOE-SR, 703-46A 